ANL-8031

LMFBR Sodium Technology

(UC-79a)

ARGONNE NATIONAL LABORATORY

9700 South Cass Avenue

Argonne, Illinois 60439

\title{
MULTIPURPOSE SODIUM SAMPLER FOR LMFBR's: DESIGN AND OPERATION
}

\section{by}

V. M. Kolba, J. T. Holmes, S. B. Skladzien, M. A. Slawecki, E. C. Filewicz, and P. A. Nelson

Chemical Engineering Division

February 1974

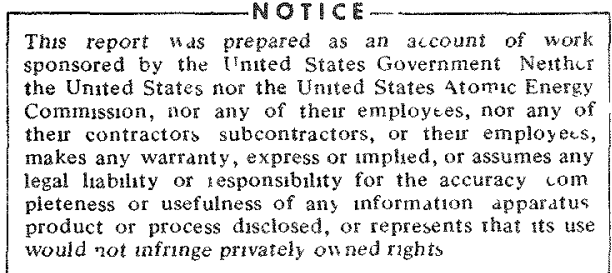

This document 18 PUBLICLY RELEASABLE Mary R. Hale, ANL Authorizing Official 


\section{DISCLAIMER}

This report was prepared as an account of work sponsored by an agency of the United States Government. Neither the United States Government nor any agency Thereof, nor any of their employees, makes any warranty, express or implied, or assumes any legal liability or responsibility for the accuracy, completeness, or usefulness of any information, apparatus, product, or process disclosed, or represents that its use would not infringe privately owned rights. Reference herein to any specific commercial product, process, or service by trade name, trademark, manufacturer, or otherwise does not necessarily constitute or imply its endorsement, recommendation, or favoring by the United States Government or any agency thereof. The views and opinions of authors expressed herein do not necessarily state or reflect those of the United States Government or any agency thereof. 


\section{DISCLAIMER}

Portions of this document may be illegible in electronic image products. Images are produced from the best available original document. 
•. . 
ABSTRACT. . . . . . . . . . . . . . . . . .

I. INTRODUCTION. . . . . . . . . . . . . . . . 2

II. DESCRIPTION OF MULTIPURPOSE SAMPLER . . . . . . . . . . 6

III. OPERATION OF THE MULTIPURPOSE SAMPLER . . . . . . . . . . . 15

IV. MULTIPURPOSE SAMPLER CONSTRUCTION . . . . . . . . . . . 17

V. MULTIPURPOSE SAMPLER TESTING. . . . . . . . . . . . 21

VI. FUTURE INSTALLATIONS. . . . . . . . . . . . 25

ACKNOWLEDGMENTS . . . . . . . . . . . . . . . . . . 25

REFERENCES. . . . . . . . . . . . . . . . . . . . . 27

APPENDIX A. REMOTE TESTING OF ŢHE MULTIPURPOSE SAMPLER ON

APPARATUS FOR MONTTORING AND PURIFYING SODIUM (AMPS) . . 28 
1. Multipurpose Sampler. . . . . . . . . . . . . . . 3

2. Multipurpose Sampler Installation Schematic . . . . . . . . 4

3. Archive-cup Insert. . . . . . . . . . . . . . . . 9

4. Specimen-equilibration Insert . . . . . . . . . . . . 12

5. Filtration Insert . . . . . . . . . . . . . . . 13

6. Multipurpose Sampler (Details). . . . . . . . . . 18

7. Multipurpose Sampler Installation on AMPS . . . . . . . . . 19

8. MS Instrument and Control Console . . . . . . . . . . . 20

9. Modification of MS Sample Cup to Hold a 4-cc Quartz Cup

10. Remote Assembly of Insert Holder and Archive-cup Insert . . . . . 24

11. FFTF Sampling Cell. . . . . . . . . . . . . 26

1-A. Impact Wrench and Sling . . . . . . . . . . . . . 30

2-A. Sling Arrangement for Lifting Spoo1 Piece and Freeze Vent . . . . 31

3-A. Piping Arrangement for Leak Checking. . . . . . . . . . . . 34

4-A. Suggested Fan Hinge Modification. . . . . . . . . . . 36

5-A. Furnace Sling . . . . . . . . . . . . . 42

6-A. Tool for Holding Inserts. . . . . . . . . . . . 45

7-A. Modified Archive-cup Insert . . . . . . . . . . . . . . 48

8-A. Spool and Funnel Arrangement for Vanadium-wire Equilibration. . . 50

\section{LIST OF TABLES}

1. Multipurpose Sampler Design Data and Criteria . . . . . . . 6 


\author{
MULTIPURPOSE SODIUM SAMPLER FOR LMFBR'S: \\ DESIGN AND OPERATION \\ by \\ V. M. Kolba, J. T. Holmes, S. B. Skladzien, \\ M. A. Slawecki, E. C. Filewicz, \\ and $\mathrm{P}$. A. Nelson
}

\begin{abstract}
A multipurpose sampler (MS) has been designed and developed for use on liquid-metal systems, including liquid-metal-cooled fast-breeder nuclear reactors. With the MS, the plant operating crew is capable of performing all of the sampling functions required for the monitoring of impurities in liquid-metal systems. These functions are as follows: (1) obtaining overflow-type cup samples, including samples that are protected from the atmosphere by frozen-metal seals; (2) high-temperature $\left(1382^{\circ} \mathrm{F}\right)$ equilibration of the impurities $(0, \mathrm{C}, \mathrm{H}, \mathrm{N})$ in the liquid metal with appropriate solid-metal specimens (the specimens are removed and easily analyzed chemically for the impurity elements, and, by using known distribution coefficients, the activities of the impurity elements in the liquid metal can be obtained); and (3) filtration sampling for particulate material in the liquid-metal systems.

The MS was designed to fit the minimal space that had been allotted for the installation of the sampler in the primary sodiumsampling cell of the Fast Flux Test Facility (FFTF).

Prototype units were fabricated and have been tested on small laboratory loops at Argonne National Laboratory (ANL) and Hanford Engineering Development Laboratory (HEDL). Sampler-component operation and overall system operation have been successfully demonstrated.
\end{abstract}




\section{INTRODUCTION}

On-line methods for obtaining overflow, ${ }^{1}$ equilibration, ${ }^{2}$ and filtration samples ${ }^{3}$ are required for monitoring impurities in liquid sodium. Equipment capable of obtaining individual samples in any one of the above modes has been used at various sites. Space availability and costs indicated the need to incorporate the three sampling modes into one modular sampler with the associated equipment for controlling the sodium temperature. A multipurpose sampler (Fig. 1) which is capable of providing these samples has been designed by Argonne National Laboratory. The MS was designed for installations where direct access is possible; however, the same design, with modifications for remote handling, will be used at FFTF. (The analytical methods and procedures used after sampling are detailed in Ref. 4.)

The MS can be used to house any one of three removable inserts, which are attached to an insert holder. The three types of inserts are (1) the archive-cup insert, (2) the equilibration insert, and (3) the filtration insert.

With the archive-cup insert, the sampler can be used to obtain overflow samples of sodium in a cup. The labyrinth-type sodium freeze seals at either end of the insert, which isolate the sample in the overflow cup, permit the sample to be handled in air. For archive purposes, the sample can be stored for long periods of time, if placed in an inert atmosphere after being sealed in a secondary container made of stainless steel. The overflow samples, obtained in a cup made of a nonreactive material, can be used for analysis of metals and interstitials, such as $0, \mathrm{H},{ }^{3} \mathrm{H}, \mathrm{C}$, and $\mathrm{N}$.

The equilibration insert permits the sampler to be used to equilibrate metal specimens with impurities in the liquid metal. Analyses of these metal specimens for $\mathrm{O}, \mathrm{H}, \mathrm{C}$, and $\mathrm{N}$, and correlation of these data to experimentally determined activity measurements permits a determination of the amount of these interstitials in the sodium to well below $1 \mathrm{ppm}$. The equilibration method is particularly useful as a primary standard for calibrating on-1ine monitors for oxygen and as a secondary calibration standard for hydrogen meters. 5 For example, the oxygen activity of the sodium is determined by equilibration of vanadium specimens, analysis of the specimens for oxygen, and reference to a curve of the distribution of oxygen between vanadium and sodium. 6 Because the oxygen activity in the sodium is related to the output voltage of the on-line oxygen monitor, the newly determined activity value serves as a calibration checkpoint for this monitor.

The filtration insert allows the collection of particulates from the flowing 1iquid metal. These particulates can be analyzed subsequently to determine the species present.

In addition to the MS and its console, the following installation equipment and hardware, shown in the schematic (Fig. 2), are required: (1) inlet and outlet isolation valves for sodium, one of which (preferably the inlet valve) has the capability of a flow-control valve for flow rates in the range from 0.1 to $0.5 \mathrm{gpm}$; (2) flow indicators, preferably in both inlet and outlet lines; however, one indicator in the outlet line is the minimum; (3) a freeze coil and a pressure gauge ( $-30 \mathrm{in}$. to $15 \mathrm{psi}$ ) in the gas line and (4) a valve for the gas line that is compatible with sodium. 


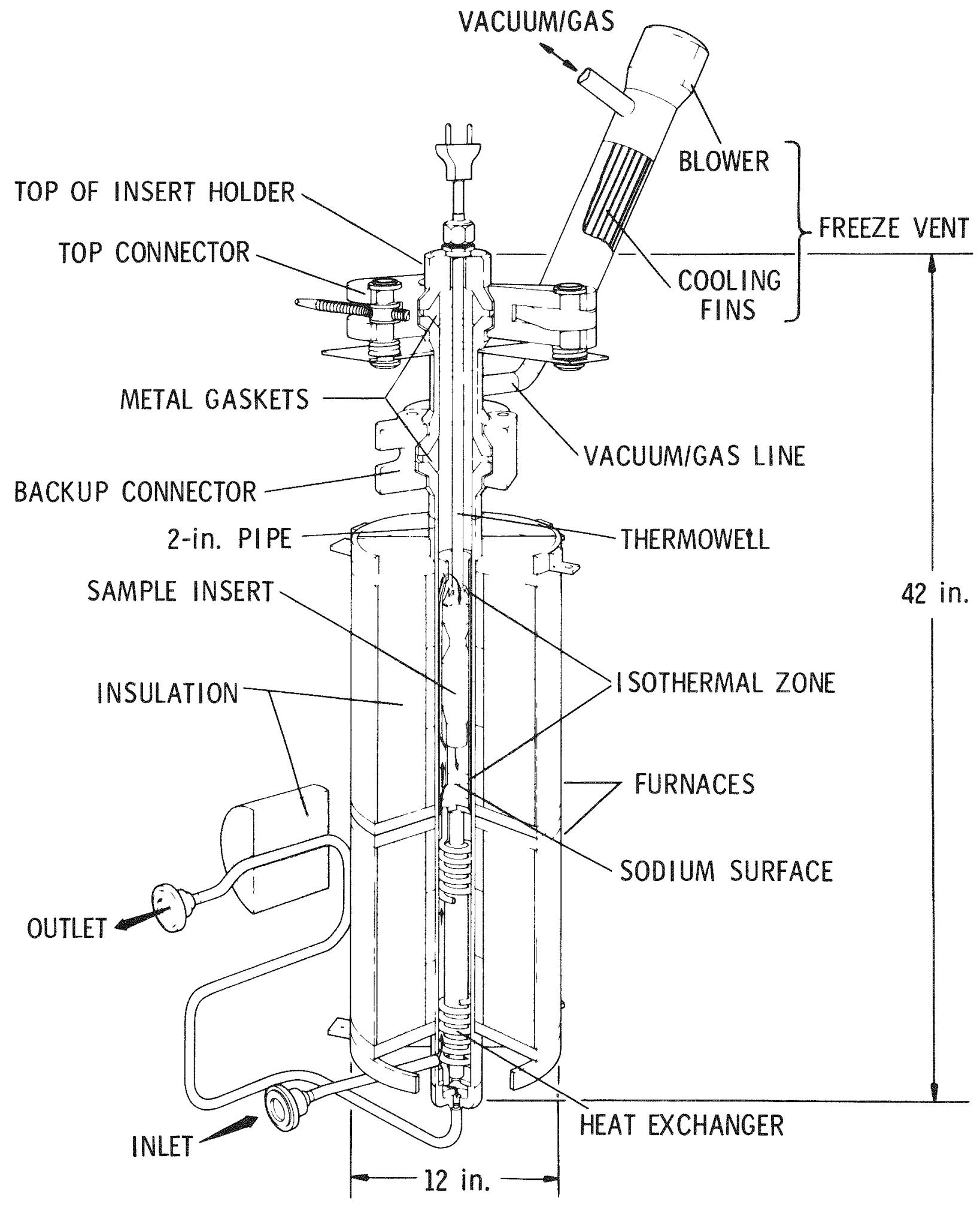

Fig. 1. Multipurpose Sampler 


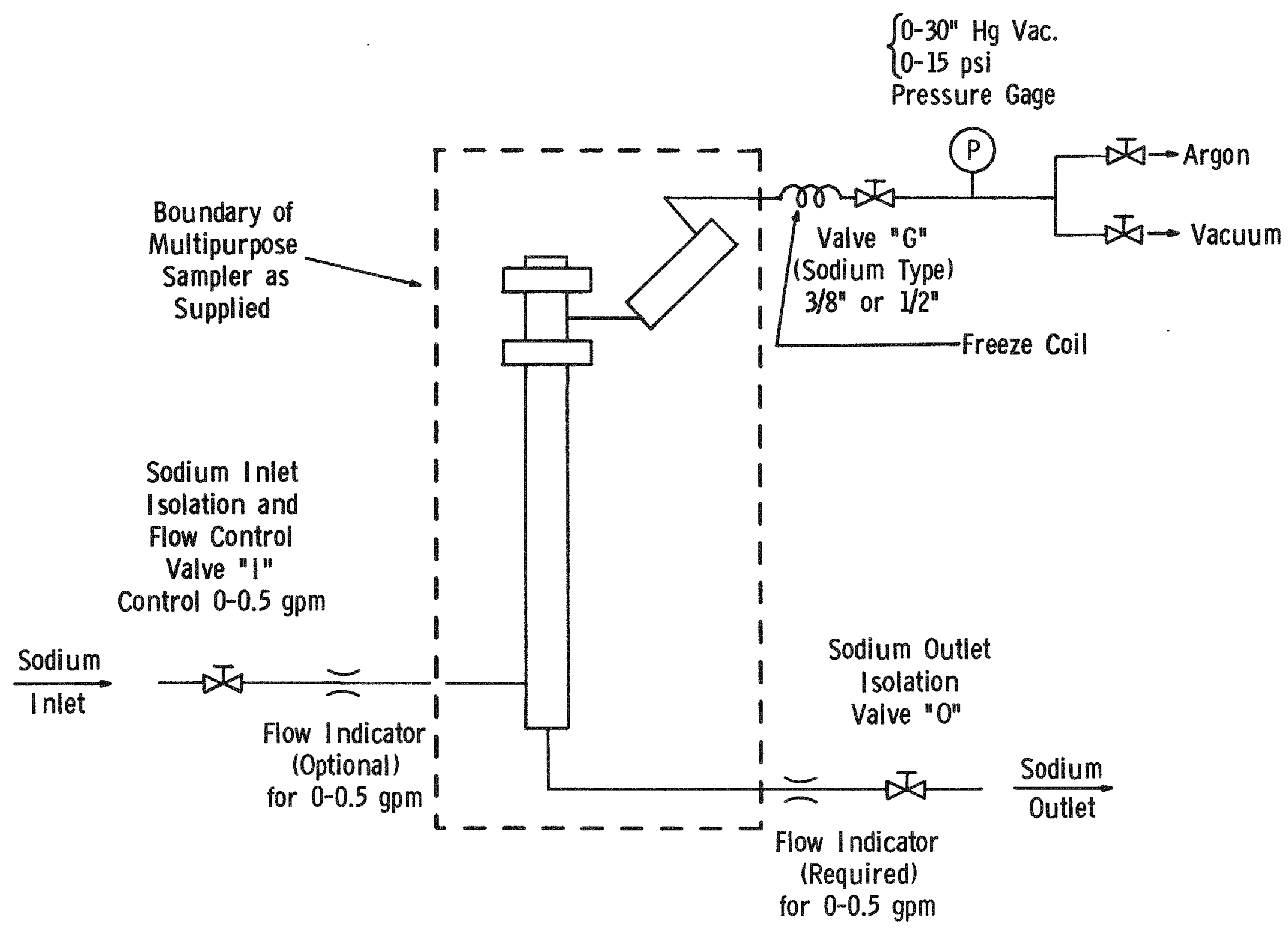

Fig. 2. Multipurpose Sampler Installation Schematic 
The gas line should be manifolded to a vacuum system and a high-purity argon or helium supply, with appropriate valving to allow operation with either vacuum or gas pressure. As a minimum, the vacuum system should have a thermocouple gauge and control unit; and, if a mechanical pump is used, a trap for pump-oil vapor will be required.

Prototype MS units have been fabricated. One is being tested at ANLIllinois on a small laboratory loop titled the Apparatus for Monitoring and Purifying Sodium (AMPS). The other is being tested on the Prototype Applications Loop (PAL) at HEDL. An RDT Standard (C 8-8) has been amended to include the multipurpose sampler within the scope of the standard. Although the sampler was designed for incorporation in liquid-metal systems that permit direct-access operation, a modified version, with remote-handling capabilities, has been designed for use in the FFTF sampling-cell package. 


\section{DESCRIPTION OF MULTIPURPOSE SAMPLER}

The MS, shown in Fig. 1, is capable of performing any of the following operations: (1) sodium sampling, including the taking of protected samples, (2) equilibration of metal specimens for analyses of oxygen, carbon, hydrogen, and possibly other impurities in sodium, and (3) sampling for particulates in sodium. The MS has an isothermal sampling zone, with furnaces and heat economizer for temperature control. The MS heats the incoming sodium to a maximum of $1382^{\circ} \mathrm{F}\left(750^{\circ} \mathrm{C}\right)$ for specimen equilibration or maintains the temperature of the inlet sodium constant in the range from 400 to $1200^{\circ} \mathrm{F}$ for overflow-cup or filtration sampling. A list of the design goals is given in Table 1 . The MS has been designed to conform with Class II of Section III of the ASME Code and Code Case 1331-5. For use at FFTF, a Class I analysis will be required.

TABLE 1. Multipurpose Sampler Design Data and Criteria

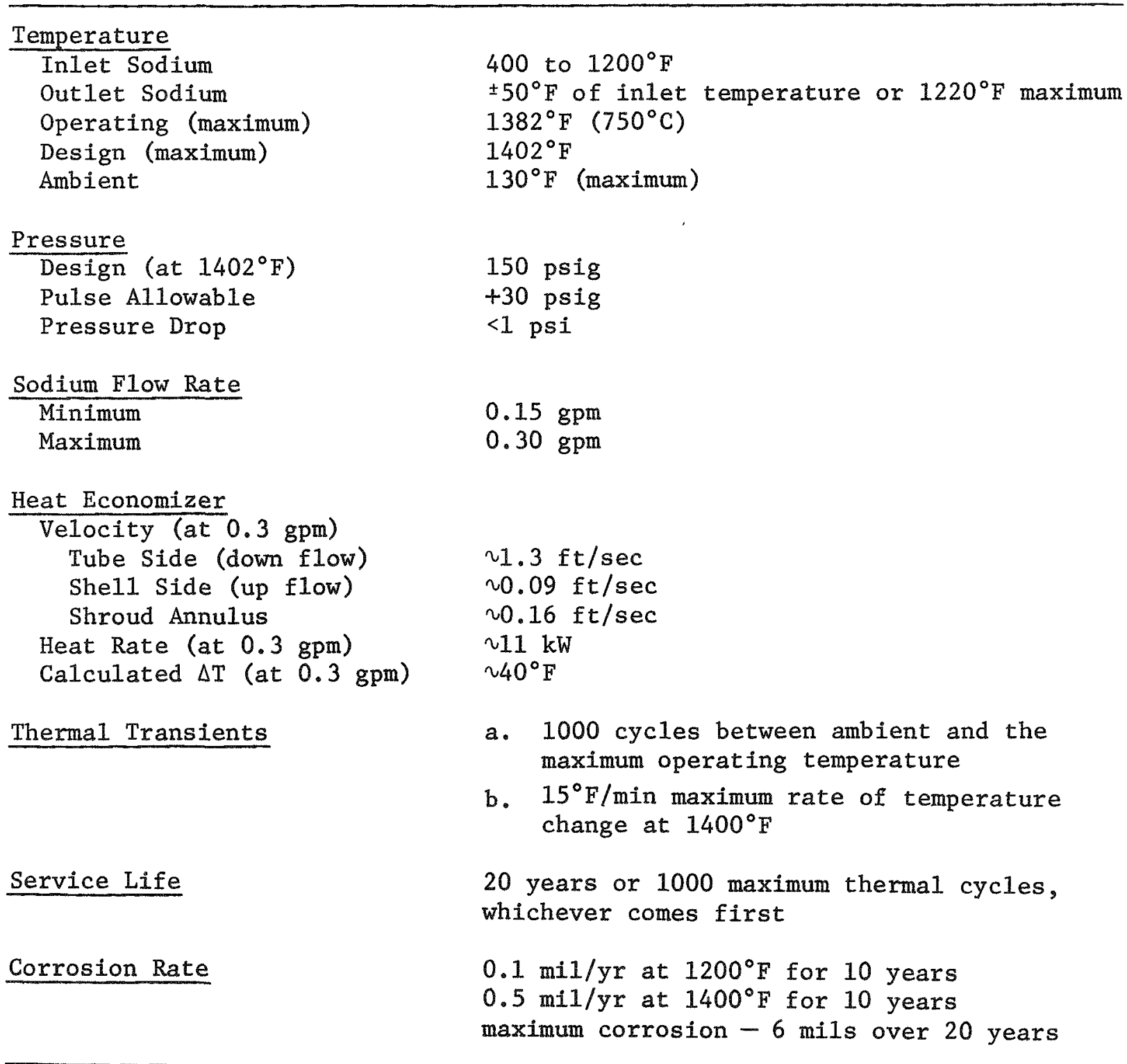


Pressure Boundary. The pressure boundary of the sampler, which separates the sodium and cover gas from the surrounding atmosphere is made of type 304 stainless steel, 2-in. schedule 40 pipe, with the bottom enclosed by a 2 -in. schedule 40 pipe cap. The sodium inlet and outlet lines are 1/4-in. schedule 40 pipe welded to the body and pipe cap, respectively. The lower plate of the heat exchanger (economizer)/shroud-tube assembly is machined to accommodate welding of this assembly to the body and pipe cap. Two Grayloc connectors, spaced about $5 \mathrm{in}$. apart, are located at the upper end of the sampler. The upper connector is used for routine insertion and removal of samples; the lower (back-up) connector is used only for the removal of the freeze vent. Standard 4-bolt Grayloc clamps are used at both positions. For remote operation, a quick-disconnect throughbolt-type Grayloc clamp is used for the lower connector and a Grayloc clamp, modified for remote operation, is used for the upper connector. Attached to the spool piece between the connectors is a branch line of 1 -in. schedule 40 pipe which leads to a freeze vent. This line allows a vacuum or inert atmosphere to be maintained in the sampler, and provides for pressure balancing during operation, if required. The freeze vent, which can be cooled or heated, has external fins and a blower for cooling, and a removable cartridge heater inserted in a thimble for heating. The purpose of the freeze vent is to prevent sodium from entering the gas line if a pressure pulse or surge occurs in the sodium, or a leak develops in the connectors.

The sampler is supported by rings at the lower and upper ends of the 2in. pipe. Two furnaces are used for heating the samplex. For direct-access application, both furnaces are hinged and supported from a structure that is attached to the lower support ring and guided by the upper support ring. (The arrangement for furnace support is not shown in Fig. 1.) For remote operation, the lower support ring supports and guides the lower furnace, whereas the upper furnace is independently supported by a hinge arrangement that is attached to the upper support ring.

Heat Exchanger. The heat exchanger (economizer) is a tube (coil)-inshe11 type fabricated from 304 stainless steel. Inlet flow is over the coils in the shell side and return flow is through the inside of a 3/8-in.-OD tube with a $0.035-1$. - thick wall; the tube is coiled around a center spacer ( $1-3 / 16-i n$. OD) to form 23 coils on a 1/2-in. pitch. The heat-exchanger coil is not a part of the pressure boundary. The design capacity of the heat exchanger is $\sim I 1 \mathrm{~kW}$ with $\Delta \mathrm{T}=40^{\circ} \mathrm{F}$ at $0.3 \mathrm{gpm}$.

A shroud tube, which has three 3/32-in.-dia inlet holes located 2-1/2 in. down from the top, is used to conduct the sodium flow along the sampler body to a position above the holes, so that a head of sodium ( 2 in.) is maintained to provide flow to the sampling region. The 304 stainless steel shroud tube (1-7/8-in. OD with a 0.049-in.-thick wall and $13-3 / 4 \mathrm{in}$. 1ong) is welded to the upper end plate of the heat exchanger. In operation, sodium exits from the shell side of the heat exchanger, flows through the annulus between the shroud tube and the sampler body, and exits to the interior of the shroud tube through the 3/32-in. holes, which provide three spouting streams of sodium into the funnel of the sample insert holder. Sufficient head is required to maintain adequate spouting (jetting) of the sodium into the central region of the shroud. 
Insert Holder. The insert holder is the mechanism by which various sampling devices (inserts) are accommodated in the sampler. The holder contains a closure flange, which completes the top seal of the sampler, a series of heat shields, a thermowell for a platinum resistance bulb (PRB), used to measure the sodium temperature, and a funnel for directing sodium flow to the insert. The closure flange, a modified Grayloc blind hub, is welded to the 7/16-in. OD, 1/4-in. ID thermowell tube. The support structure for the funnel and immersion well is welded to the thermowell tube near the tip end. The region of the insert holder, containing the support structure, funnel, and immersion well, is shown in the top portion of Fig. 3. The funnel directs the flow of the incoming sodium via holes in the funnel wall to the attached insert and through the funnel bottom to the immersion well. The immersion well, with a 1/16-in.-dia drain hole at the bottom, surrounds the tip of the thermowell and provides a constant level of sodium around the thermowell to form an isothermal zone required for accurate temperature measurements. Three pins at the periphery of the funnel and bayonet slots on the inserts provide the means of attaching the insert. Surrounding the thermowell and supported by the funnel attachment weldment is a tube with cone-shaped heat shields spaced at $\sim 3 / 4-i n$. intervals. These prevent sodium vapor from reaching the closures or freeze vent during normal operation.

Freeze Vent. The freeze vent is a protective device that prevents sodium from entering the inert gas/vacuum line above the MS. Design of the vent is based on extrapolated data (AI-AEC-13022, January 31, 1972) which indicate that with a $100^{\circ} \mathrm{F}$ freeze-vent temperature, an 8-in. Iong 0.050-in. annulus is adequate to stop $1200^{\circ} \mathrm{F}$ sodium at a velocity of $20.5 \mathrm{ft} / \mathrm{sec}$ in the annulus.

The freeze vent consists of a 1-in. schedule 40 pipe that is welded to the spool piece. A 12-in. long thimble, machined to $0.950-$ in. OD, provides space for a removable cartridge heater. A 0.050-in. annulus between the outer side of the thimble and the inner side of the pipe is maintained for gas flow. When required, this annulus provides adequate surface for the formation of a sodium freeze plug. Twenty 3/8-in.-high cooling fins, 8 in. long, are spaced on the periphery of the 1-in. pipe. A shroud of 2.5-in.-OD tubing surrounds the fins and directs the flow of cooling gas at ambient temperature. A blower provides a $100 \mathrm{cfm}$ gas stream. A cartridge-type heater is placed in the 12-in.-1ong thimble so that the freeze plugs can be remelted.

MS Furnaces, and Instruments. The electrical console for control of the sodium system of the sampler is also a part of the MS. Its functions include temperature control and recording, and alarm actuation.

Heating of the sampler is accomplished by two furnaces 10 in. in dia by 12-1/4 in. 1ong. The furnaces are split axially to permit assembly around the sampler. Each furnace has three separate axial heating zones (top, mid, and low) of 600 watts for a total capability of about $1800 \mathrm{~W}$ at $57.5 \mathrm{~V}$. Thermocouple sensors are placed at each of the three axial zones in both the top and bottom furnaces. A number of temperature-control options were tested and found to give adequate temperature control for specimen equilibrations and for overflow sampling and filtration operations at lower temperatures. The options tested were as follows: 


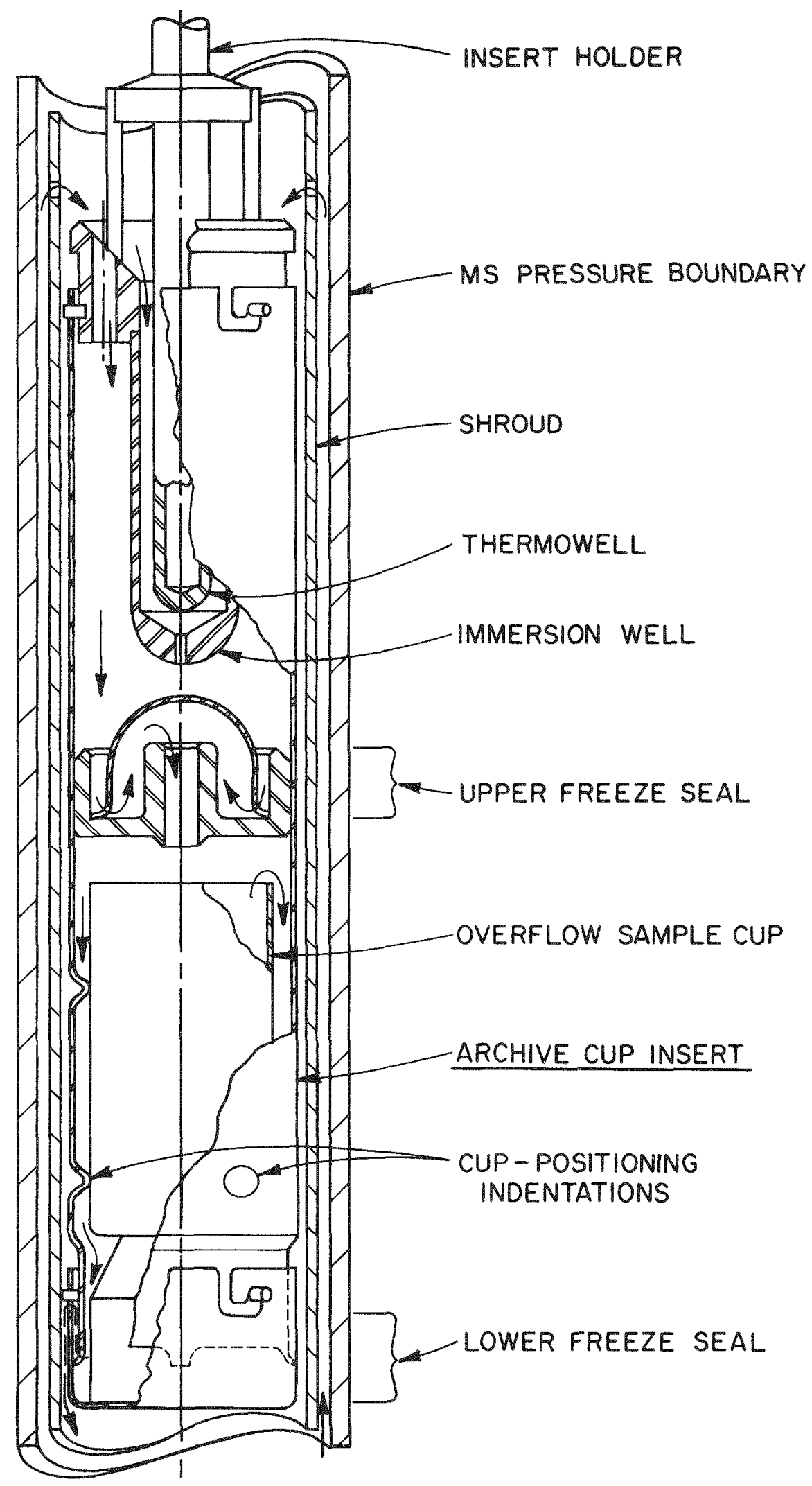

Fig. 3. Archive-cup Insert 
A. The low zone of the top furnace was controlled by a two-mode automatic controller (proportional and reset) with a silicon controlled rectifier (SCR) power output. A thermocouple temperature sensor in that zone of the furnace was used as the signal to the controller. The controller set point was adjusted to give the desired sampling or equilibration temperature as indicated by the $\mathrm{PRB}$ in the thermowell of the insert holder. Individual variable-voltage transformers were used to manually adjust the power input to each of the other five furnace zones (all three zones in the bottom furnace and the mid and top zones of the top furnace) to achieve the desired temperature distribution.

B. The top zone of the bottom furnace and the low and mid zones of the top furnace were combined in parallel and controlled by the two-mode controller with SCR power output. A thermocouple sensor (in the low zone of the top furnace) was used as the signal to the controller, and the set point was adjusted as in option $A$. A variable-voltage transformer was used to adjust the power input to the top zone of the top furnace, and a separate unit was used for the combined low and mid zones of the bottom furnace, again to achieve the desired temperature distribution.

C. The same furnace-zone management as in B was used. A thermocouple sensor was located in the thermowell of the insert holder, and the controller set point was adjusted to the desired equilibration or sampling temperature. It should be noted that using a thermocouple in the thermowell of the insert holder does not allow sufficient space for the PRB that is normally used for accurately monitoring equilibration temperatures. A smaller diameter PRB or a second calibrated thermocouple could be used for this option.

Trace heaters are used on the gas lines and a cartridge-type heater is installed in the freeze vent. Temperatures are recorded on.a multipoint recorder except for the output of the $\mathrm{PRB}$, which is continuously recorded on an instrument having ranges from 0 to $750^{\circ} \mathrm{C}$ or from 650 to $800^{\circ} \mathrm{C}$.

High-temperature alarms are provided for both the MS body and the freeze vent.

Archive-cup Insert. The archive-cup insert, shown in Fig. 3, is a device for obtaining an overflow-cup sample which, by the use of labyrinth-type sodium freeze seals, will be protected* from the atmosphere during removal from the MS. It consists of a 1-1/2-in.-OD tube, which forms the radial boundary of the insert. The upper end has the bayonet connector for attachment to the specimen insert holder. The upper labyrinth is formed by a cap which is press-fitted into a machined bulkhead. This assembly is inserted into the tube and plug-welded to the tube near the midpoint of the insert. After welding, the welds are machined flush and a tube-reducing operation is performed to assure a tight fit. At the lower end of the insert, a removable cap with an attached pedestal, which supports the sample cup, is coupled to the tube by a bayonet connector to form the lower labyrinth.

\footnotetext{
"Protected" here means that the sodium sample will not be allowed to contact air (or other atmosphere) en route from the sampler to the analytical laboratory. This aspect is extremely important for obtaining sodium samples for archive purposes.
} 
Preparatory to use, the components are cleaned to remove contaminants. The overflow cup is placed on the pedestal of the removable cap, and this assemblage is inserted into the body of the insert from the bottom and coupled by the bayonet connector. The archive-cup insert is attached to the insert holder before placing this assembly in the sampler. During operation, sodium enters at the top of the insert from the funnel in the insert holder. It then flows through the upper freeze-seal labyrinth and through a 1/4-in.OD hole in the bulkhead, from which it drops directly into the sample cup. After the sample cup fills, the sodium overflows the cup and then follows a path through the lower freeze-seal labyrinth back to the tube side of the heat exchanger. At the end of a sampling run, the frozen sodium in the upper and lower labyrinths isolates the sodium in the sample cup from contact with the external environment. After removal of the insert holder from the sampler, the archive-cup insert is uncoupled from the insert holder. Disassembly of the archive-cup insert to remove the sample cup is done in an inert atmosphere. The region of the insert including the removable cap is placed in a special fixture that has clamps to hold the removable cap, and a heater. The region of the removable cap is heated to the melting point of the sodium in the freeze seal and the insert tube is removed, leaving the exposed sample cup on the pedestal of the removable cap.

Tantalum or stainless steel sample cups, having a 1.2-in. OD, a 0.020-in.thick wall and $2.4 \mathrm{in}$. high, are being used. Quartz cups can be accommodated for samples that are to be used for carbon and helium analysis.

Specimen-Equilibration Insert. The specimen-equilibration insert shown in Fig. 4 is a device for containing and exposing specimens (wires, foils, tabs, etc.) to flowing sodium at the equilibration temperature, normal1y $750^{\circ} \mathrm{C}$. It consists of a 1-1/2-in.-OD tube with a bottom having a 1/16-in. weep hole. The upper end has a bayonet connection for attachment to the insert holder. A small internal ring or a series of indentations supports a removable funnel which has an end terminating about $1 / 2$ in. from the bottom of the unit. Specimens to be equilibrated may be in the form of wires, tabs, or foils. These specimens are supported on removable wire racks which fit in the annulus formed between the inner surface of the insert tube and the outer surface of the funnel spout.

During operation, sodium enters at the top of the insert from the insert holder, and flows through the internal funnel to the bottom of the insert. It then flows upward outside the funnel, past the specimens, until it leaves the insert through several 1/4-in. holes located below the funnel supports. The sodium then enters the tube side of the heat exchanger to return to the distribution system. At the termination of a run, the flow is shut off and, within $45 \mathrm{sec}$, the sodium drains away from the specimens via the weep hole. The temperature is then reduced to room temperature, and the specimens removed for analysis.

Filtration Insert. The filtration insert, shown in Fig. 5, is a device for obtaining particulate samples from the sodium in the system. It consists of a 1-1/2-in.-OD tube, containting the bayonet fitting which is welded to a tubular filter section that is $\sim 5$ in. 1ong. The filter is a sintered composite having two layers. The inner layer has a nominal 10-m $\mu$ absolute pore size and the outer layer has a $100-\mathrm{m} \mu$ absolute pore size. A solid bottom is welded to the cylindrical filter section. During operation, sodium enters 


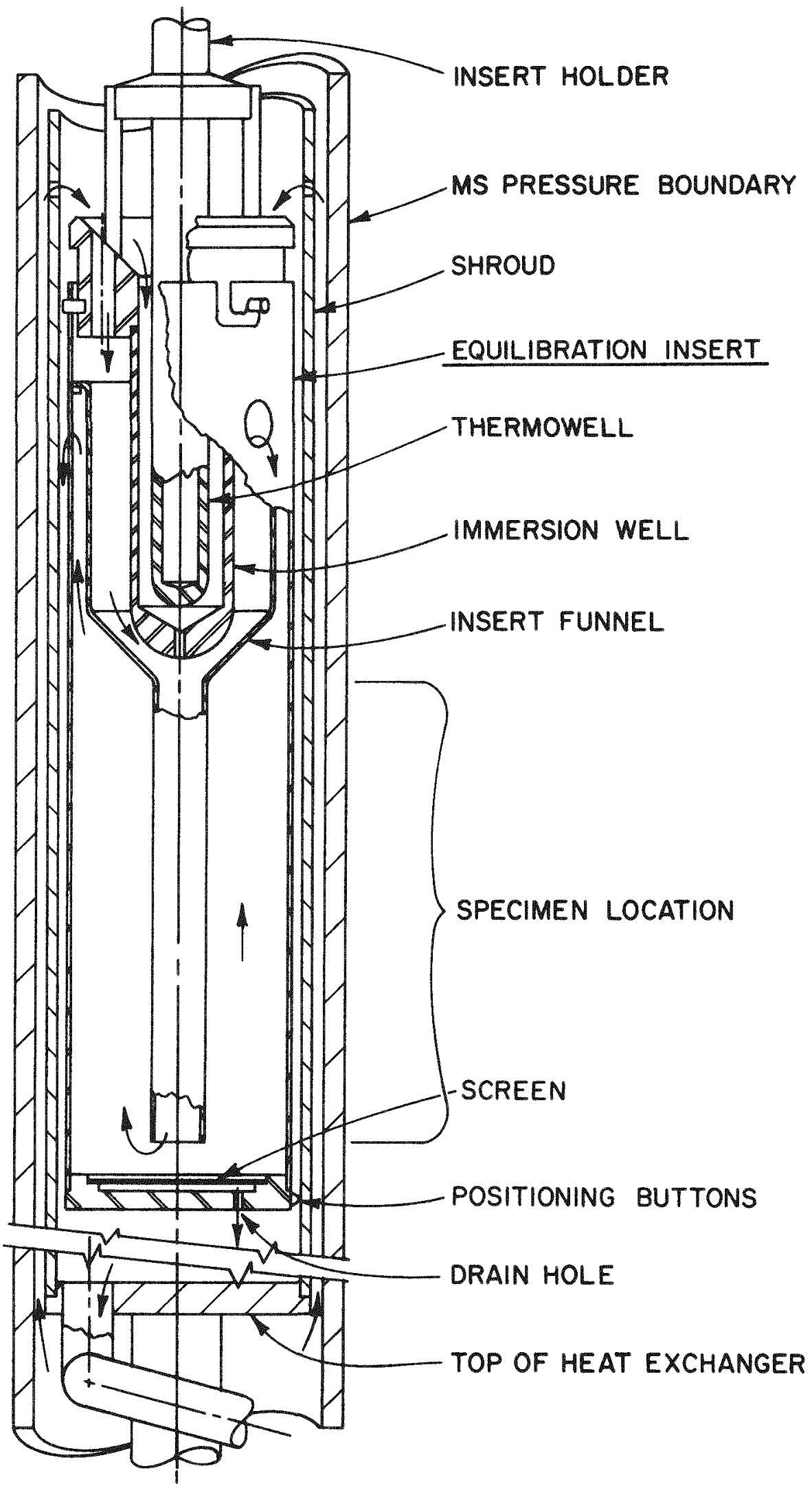

Fig. 4. Specimen-equilibration Insert 


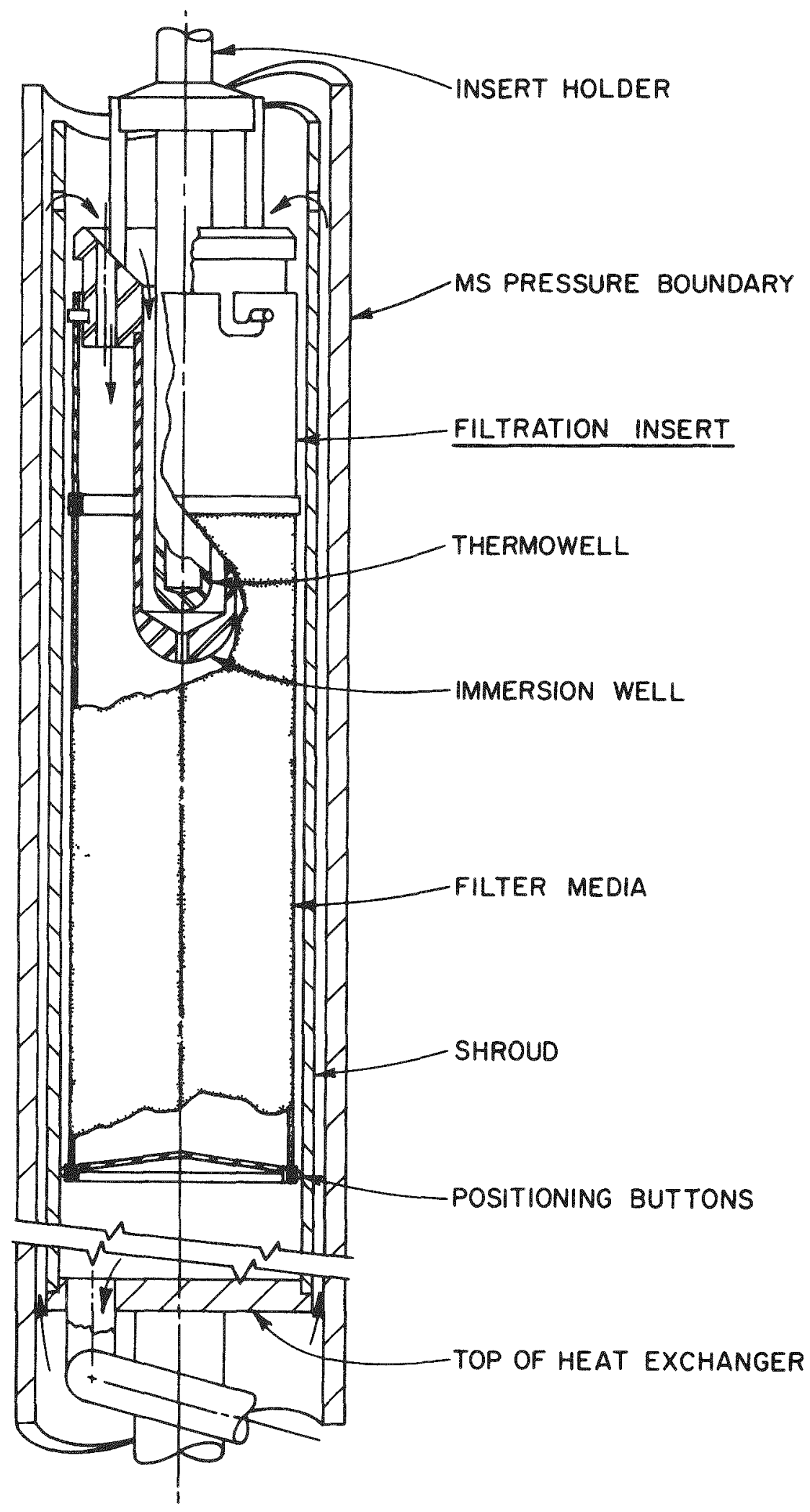

Fig. 5. Filtration Insert 
the top of the insert from the funnel on the insert holder. The sodium level rises in the filter insert until sufficient head is attained to force the sodium radially outward through the filter. Sodium then flows to the tube side of the heat exchanger.

A protected (from atmospheric contamination) filter sample can be obtained by using the archive cup insert with a cup having filter media side walls. 


\section{OPERATION OF THE MULTIPURPOSE SAMPLER}

In operating the MS, knowledge of the inlet and outlet system pressure and proper adjustment of the sodium flow rate are needed to obtain sufficient head to allow sodium spouting while not overflowing the top of the shroud.

Before MS operation begins, the operating pressure of the sodium supply system to which the MS is attached is determined. After the MS is assembled with the appropriate insert and leak-checked to ensure tightness, a vacuum of less than 10 Torr is obtained and the system is backfilled with argon. This procedure is repeated several times to purge the system. The system is then filled with argon to obtain a pressure slightly below the system operating pressure and the gas-line valve is closed to isolate the MS. The heating sequence is started from the top zone of the upper furnace and progresses down to the inlet and outlet lines, as each zone reaches about $350^{\circ} \mathrm{F}$. Pressure in the MS may have to be relieved through the gas line during heatup. When the MS body is about $350-400^{\circ} \mathrm{F}$, heating of the inlet and outlet lines to the isolation valves is begun, and finally the isolation valves and bonnets are heated to within $50^{\circ} \mathrm{F}$ of the supply system sodium. All portions of the MS and supply/return lines are then heated to within $50^{\circ} \mathrm{F}$ of the main supply system. Care must be taken to ensure that the temperature of the flow indicator is above the melting point of sodium. The MS gas pressure is adjusted to 21 psig above the sodium supply system pressure and the argon gas valve is closed. The gas-line isolation valve remains open. Since small amounts of excess gas in the module will be expelled with the sodium through the return line when sodium flow has begun, the sampler pressure should be noted at this time for future reference. The amount of gas expelled to the return line will be minimized or eliminated by proper adjustment of the amount (pressure) of gas originally put in the MS prior to starting sodium flow.

The sodium inlet isolation valve is then cracked open and changes in gas pressure, system temperatures, especially of the PRB in the thermowell, and sodium flow rate on the inlet flow indicator should be noted. Immediately thereafter the outlet isolation valve is completely opened and the flow rate noted on the flow indicator in the outlet line. The flow is then adjusted by throttling the inlet valve until a flow rate of $0.25 \pm 0.05 \mathrm{gpm}$ is reached. The change in gas pressure should approach the supply system pressure. A sodium level will be established at the bottom of the sampling chamber. Major oscillations in the outlet flow indicator indicate that the excess gas is leaving the sampler. Once the sodium flow and level are established, no change will take place unless the supply system pressure changes or a leak in the gas system occurs.

After the sodium flow is established, the sampler temperature is adjusted for the desired operational mode. If overflow samples are being taken using the archive-cup insert or if filtration samples are being taken, the insert must be wetted to remove residual contaminants and to obtain proper operation of the insert. Wetting of the insert is obtained by operating the MS using an appropriate time-temperature relationship, e.g., if the temperature of the bulk system is $600^{\circ} \mathrm{F}$, the insert should be wetted by operation at $800^{\circ} \mathrm{F}$ for about $4 \mathrm{hr}$. After the wetting, the temperature of the sampler is reduced to $600^{\circ} \mathrm{F}$ (the bulk-sodium temperature), and the sample collected. For equilibration samples, the sampler is heated to the required 
equilibration temperature (generally $>800^{\circ} \mathrm{F}$ ) and operated for a period such that the equilibration for oxygen, carbon, or hydrogen is assured.

Preparatory to terminating the run, the gas-line valve is closed and the argon pressure is adjusted to 20.5 to 1.0 psi above the system pressure, as initially measured on the pressure gauge. The run is terminated by closing the sodium inlet isolation valve and opening the gas-line valve to admit argon gas, which forces sodium out of the return line. Upon observing flow instabilities (due to gas bubbles) on the exit flow indicator, the sodium outlet isolation valve and the gas-line valve are closed. The heaters on the system are then turned off, and the sampler is allowed to cool to room temperature before opening it up to remove the insert holder, insert, and samples. 


\section{MULTIPURPOSE SAMPLER CONSTRUCTION}

Two prototype samplers have been fabricated. One MS has been tested at ANL-IIlinois on AMPS. The other MS was fabricated at HEDL and has been tested by HEDL on the PAL. Both MS's were operated in all three sampling modes. Fig. 6 shows an exploded view of the components of a prototype MS. The sampler, except for lines and the freeze vent, may be mounted in a space 12 in. by 12 in. by 48 in.

The MS, as initially installed on the AMPS for remote testing, is shown in Fig. 7. Here the furnace zone and the furnace support and guide structures are shown. Later in the testing phase, furnaces were installed on the MS. The upper furnace is hinged and may be swung open at the completion of a run to speed the cooldown of the sampler so that the sample insert can be removed more rapidly. The furnace heaters are nichrome wire embedded in a ceramic. The inlet, outlet, and gas-line heaters are stainless steel-sheathed, mineralinsulated, wrap-on heaters. All temperature readings are obtained with swaged stainless steel-sheathed chromel-alumel thermocouples, except those obtained by the single platinum resistance bulb in the insert holder. The instrument and control console for use with the sampler is shown in Fig. 8. Temperature control of the preheat and isothermal zones of the furnaces is accomplished using silicon controlled rectifier (SCR) controllers. These are the zero voltage firing stepless-type to reduce the effect on instrument noise. Other furnace zones and heaters are served from Variacs.

Temperature-limit controllers are used for high-temperature alarms. A special single-pen recorder having a switch-selectable range of 0 to $750^{\circ} \mathrm{C}$ or 650 to $800^{\circ} \mathrm{C}$ is provided for readout of the platinum resistance bulb. All thermocouples are read on a dual scale $\left(0-800^{\circ} \mathrm{C} ; 0-1500^{\circ} \mathrm{F}\right)$ temperature indicator, coupled to a multi-point thermocouple selector switch. 


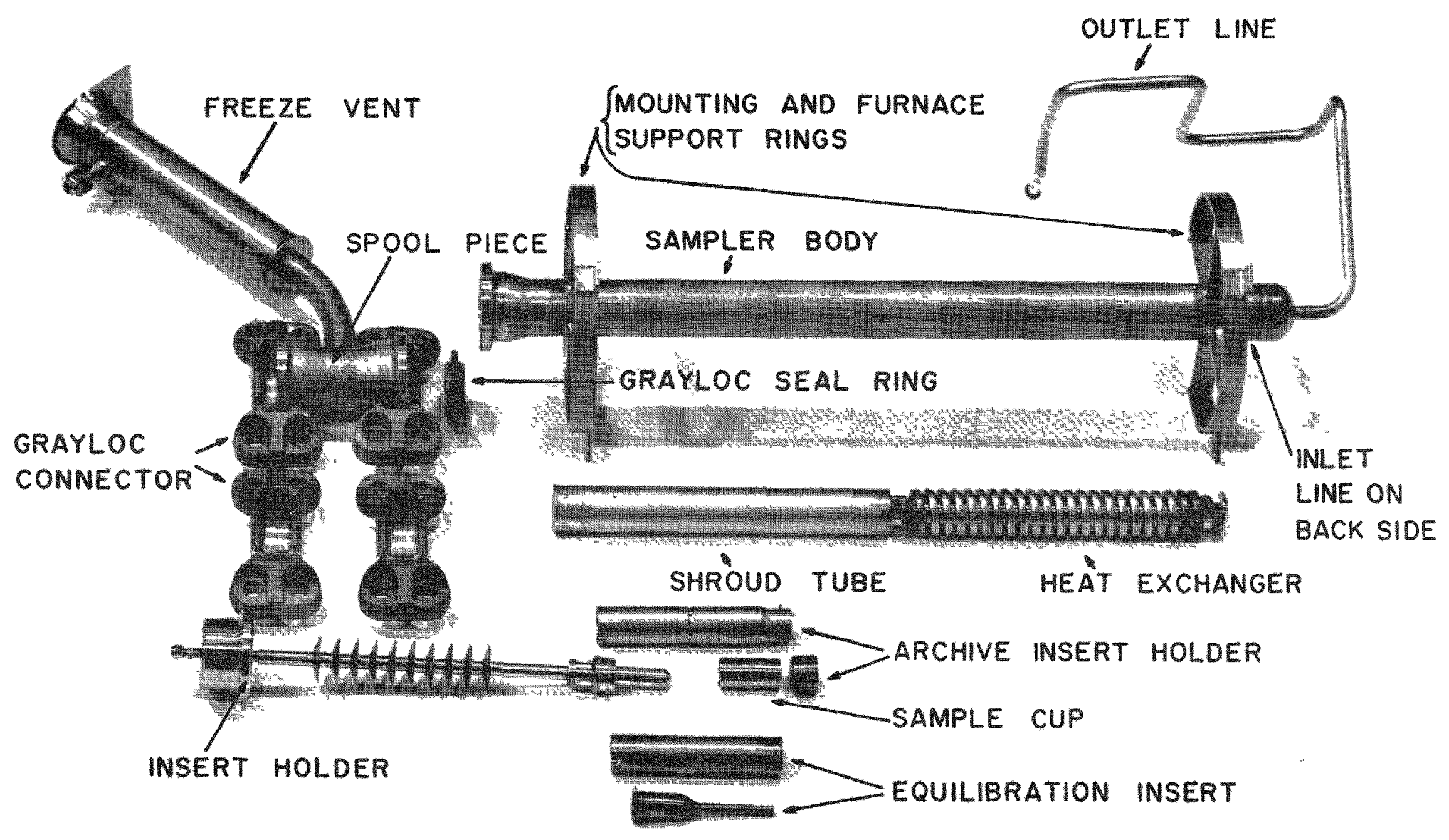

Fig. 6. Multipurpose Sampler (Details). ANL Neg. No. 308-3227A. 


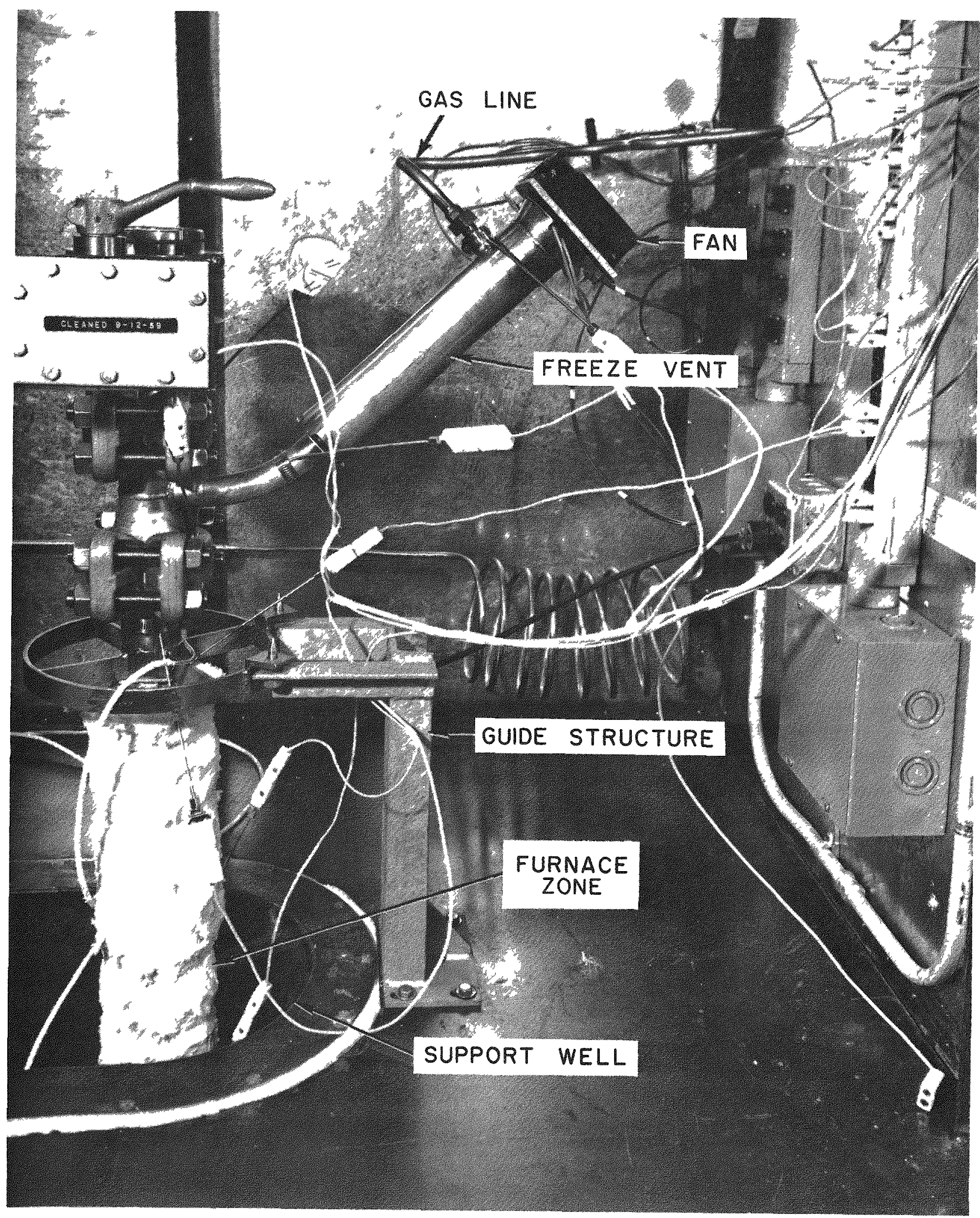

Fig. 7. Multipurpose Sampler Installation on AMPS. ANL Neg. No. 308-3248A. 


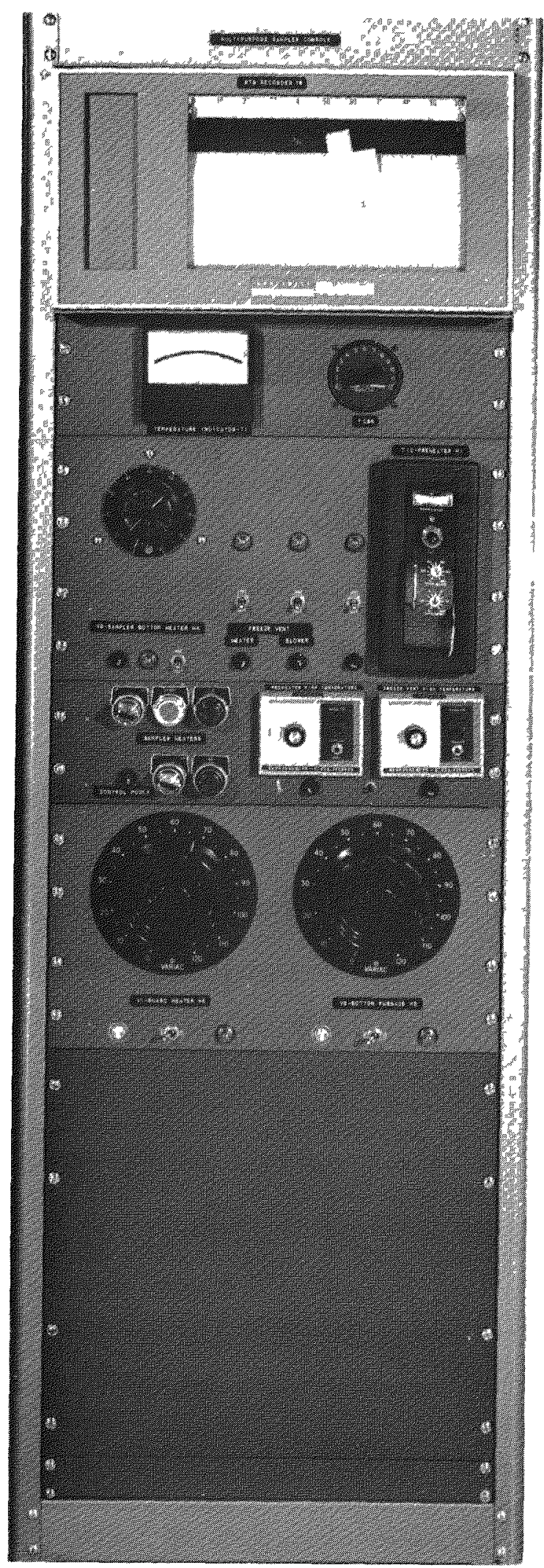

Fig. 8. Multipurpose Sampler Instrument and Control Console. ANL Neg. No. 308-3376. 


\section{MULTIPURPOSE SAMPLER TESTING}

In initial testing of the MS at ANL-I11inois, the capabilities of the unit in meeting flow and temperature-control requirements were determined. The sampler was designed to heat an incoming sodium stream with a flow rate of up to $0.3 \mathrm{gpm}$ from 400 to $1382^{\circ} \mathrm{F}\left(750^{\circ} \mathrm{C}\right)$ and to discharge the sodium at a temperature not greater than $50^{\circ} \mathrm{F}$ above the inlet temperature. In these tests, the sodium inlet temperature was varied from $400^{\circ} \mathrm{F}$ to $1125^{\circ} \mathrm{F}$, and with a flow rate of $0.3 \mathrm{gpm}$, the inlet-outlet temperature difference was less than $50^{\circ} \mathrm{F}$ in all cases.

Proper flow distribution from the holes in the shroud tube to the insert holder at the appropriate flow rate is a requirement. To investigate this, a view-port was attached to the upper Grayloc. The degree of jetting from the 3/32-in. holes in the shroud tube and the sodium level above the heat exchanger were determined visually and related to the sodium flow rate. These tests establish that a minimum flow of $20.15 \mathrm{gpm}$ is required for the initiation of adequate jetting and that $\sim 0.3 \mathrm{gpm}$ is the maximum flow rate that can be tolerated before sodium flows over the top of the shroud. While the latter should not create a great problem, flow rates that are too high may compromise the capacity of the heat exchanger. Tests showed that flow rates of 0.2 to $0.3 \mathrm{gpm}$ resulted in sodium levels in the sampling chamber of up to $0,1-1 / 4$ in. above the heat exchanger. Under stable system conditions, these levels remained steady during runs of long duration. These levels are well below the bottom of the longest insert (archive-cup insert).

Archive-cup inserts containing overflow samples, taken at $800^{\circ} \mathrm{F}$ were removed from the MS at room temperature in air and stored in a plastic container for two weeks. When the sodium samples were removed from the insert they were found to have bright sodium surfaces with no visible evidence of oxidation. Another insert opened after 10 weeks of storage also revealed a bright, unoxidized sodium sample. This qualitatively verifies the effectiveness of the frozen-metal labyrinth seals in the insert. For long-term storage, $i . e$., months to years, it is recommended that the archive-cup insert and contents be stored in a secondary sealed container containing an inert atmosphere.

Testing has shown that to obtain a good labyrinth seal, the insert, and especially the surfaces of the labyrinth seal, must be thoroughly wetted by the sodium. This has been accomplished by flowing sodium at $800^{\circ} \mathrm{F}$ through the insert for about $4 \mathrm{hr}$. If samples at lower temperatures are required, i.e., if the bulk system temperature is $<800^{\circ} \mathrm{F}$, the insert should first be wetted at $800^{\circ} \mathrm{F}$ and the temperature then reduced to that of the bulk system; the sample is then taken at the temperature of the bulk system.

When equilibration samples are taken, especially vanadium specimens, it is necessary to cool them quickly at the end of the equilibration period to avoid significant pickup of additional oxygen by the specimens during the cooling (the equilibrium oxygen content of the specimens increases as the sodium temperature decreases). To circumvent this problem, the termination of an equilibration run is accomplished by shutting off the sodium flow at the inlet valve, displacing some sodium from the sampler by argon, and closing the outlet valve. Residual sodium in the equilibration insert drains out in 
about $45 \mathrm{sec}$ through the hole in the bottom of the insert. This rapid removal of the sodium from the specimens prevents any reequilibration. The heat is then turned off and the upper furnace is swung open, away from the sampler, to allow more rapid cooling. This also accelerates the turnaround time, permitting relatively rapid $(<12 \mathrm{hr}$ ) recycling of the system for a new analysis. This latter aspect is an additional benefit when analyses are to be repeated in a short time span.

To date, the sampler at HEDL has been used to obtain 12 overflow samples, 17 equilibrations for oxygen, 5 equilibrations for carbon, and 2 filtration samples. At ANL, the sampler has thus far been used to obtain 5 overflow samples and 2 equilibrations for oxygen. The 5 overflow samples were for use in determining tritium. A standard stainless steel cup (used in the archive insert of the MS) was modified to contain a small quartz ( $12 \mathrm{~mm}$ high by $24-\mathrm{mm}$ dia) cup capable of holding 3 to 4 grams of sodium. Drain holes were provided in the bottom of the stainless steel cup to allow the overflow from the quartz cup to drain out. Two photographs of the modified stainless steel cup and the quartz cup are shown in Fig. 9.

Although some impurities are introduced into the system by opening the sampler and installing new inserts, the impurity level is relatively low and fairly reproducible, being of the order of $0.1 \mathrm{~g}$ of oxygen and $0.01 \mathrm{~g}$ of hydrogen.

The remote-handling and tooling requirements for the MS samplers, which will be installed in the FFTF sampling cell, were investigated with a MS installed on AMPS. A11 handling operations using remote means were successfully conducted with sodium present. Figure 10 shows the remote operation for attachment of the archive-cup insert to the insert holder using a crane and manipulators. Appendix A gives a summary of the remote testing performed on AMPS. 

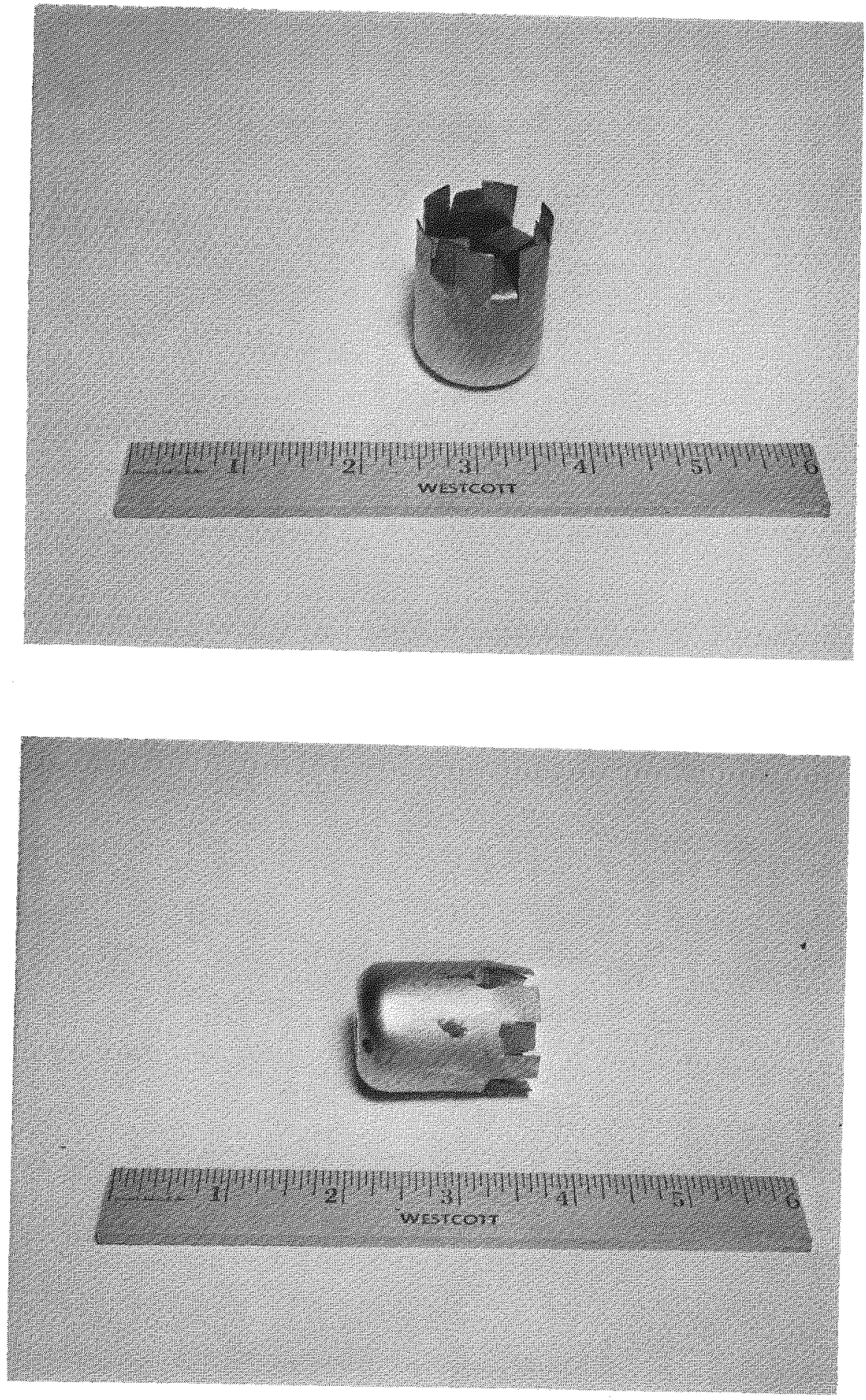

\section{Fig. 9. Modification of MS Sample Cup to Hold a} 4-cc Quartz Cup for Tritium Sampling 


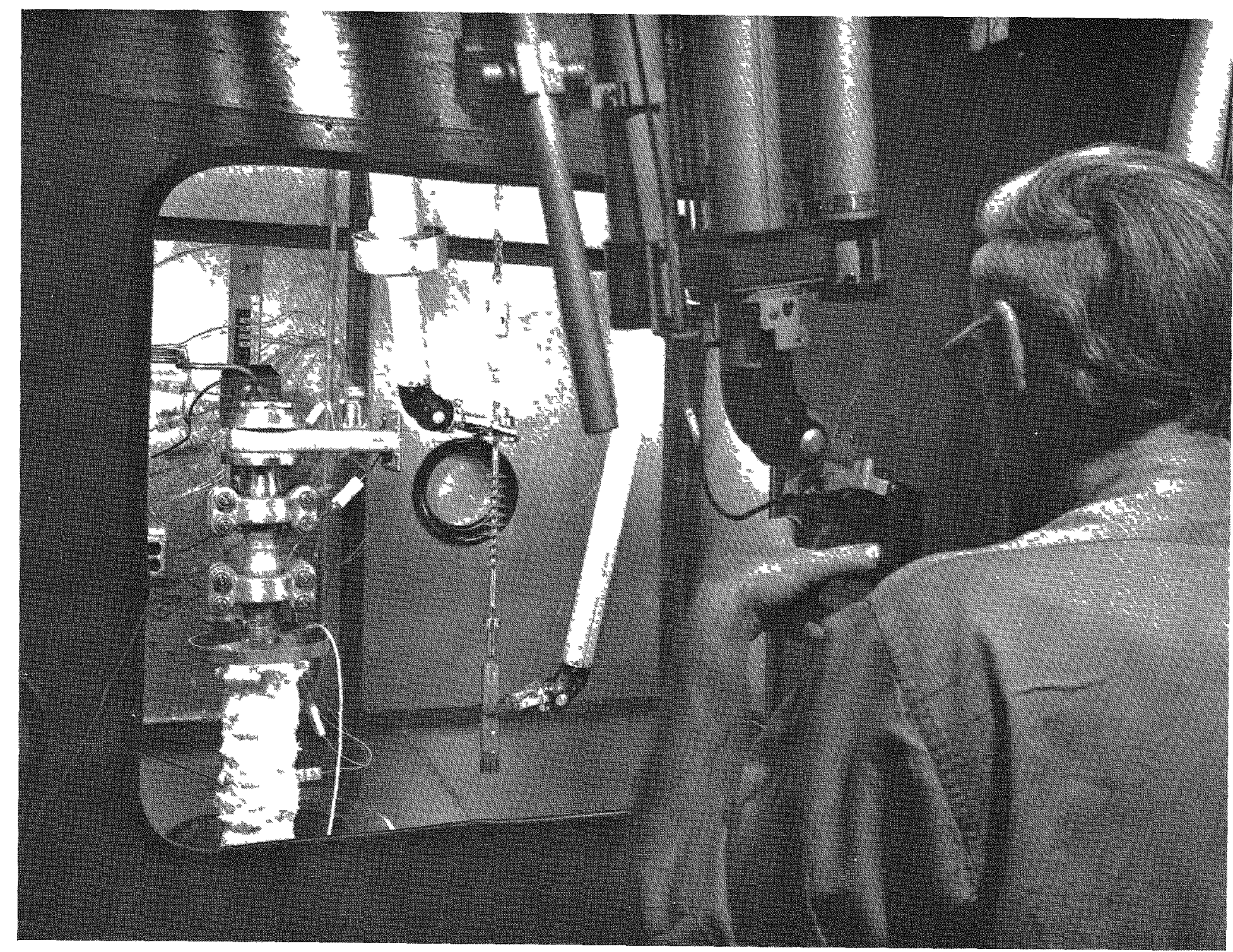

Fig. 10. Remote Assembly of Insert Holder and Archive-cup Insert. ANL Neg. No. 308-3247, 


\section{FUTURE INSTALLATIONS}

Because of the success of the testing and the potential multiple uses of the MS, installations of the MS are being planned on most of the major technology-support loops in the LMFBR development program. Plans are also being firmed for the installation of ten MS's for remote operation at the FFTF reactor. The FFTF sampling cell with ten multipurpose samplers is shown pictorially in Fig. 11 .

\section{ACKNOWLEDGMENTS}

The authors wish to acknowledge J. Kincinas, C. Wach, and D. J. Raue of the ANL Sodium Technology Program, and A. Hryn of Central Shops for valuable assistance during the fabrication and testing phases of the project. The programmatic guidance of L. Burris, Manager of the ANL Sodium Technology Program, is also gratefully acknowledged.

The efforts of Doreen Prucha, who typed the manuscript, are gratefully acknowledged. 


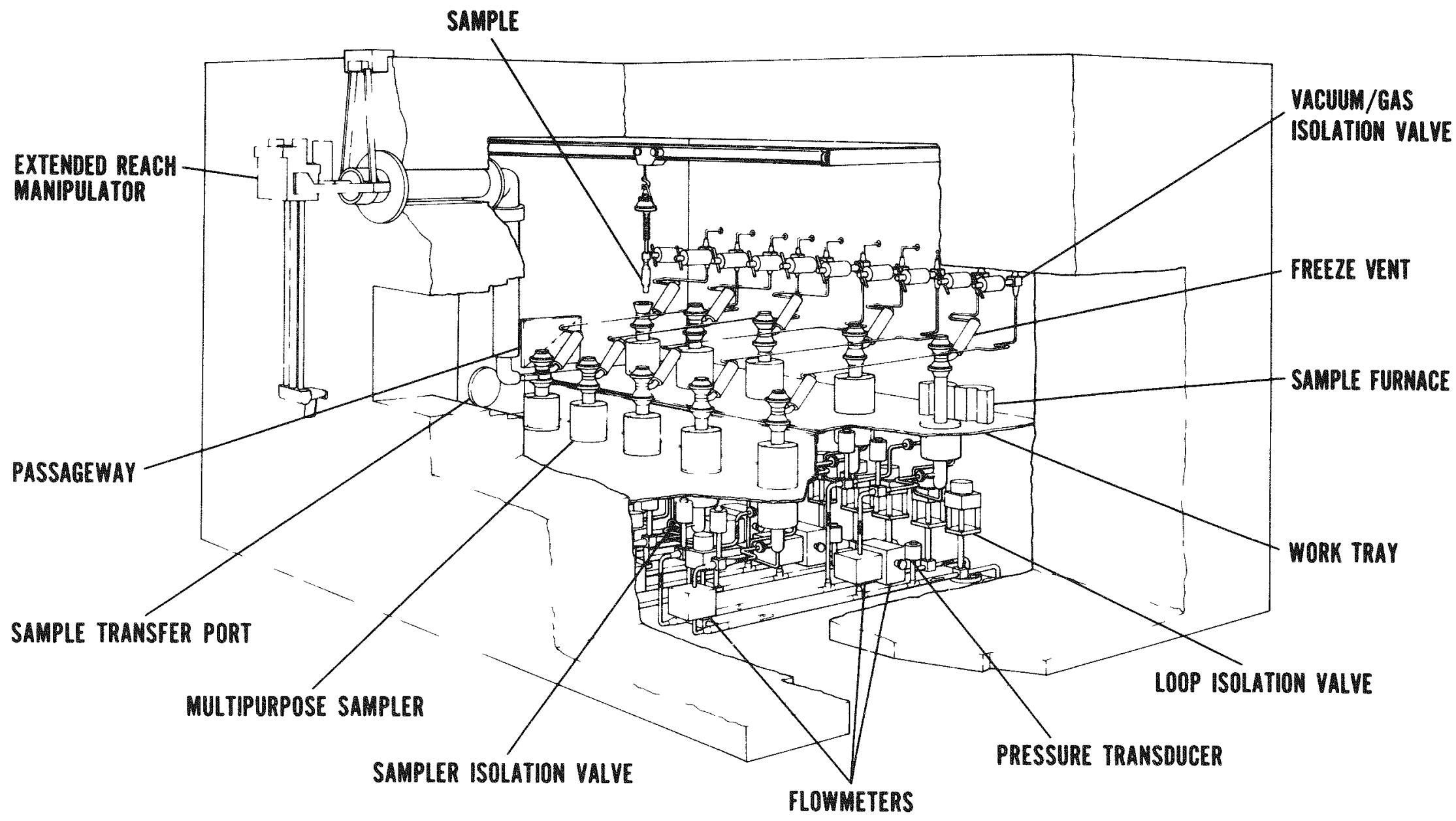

Fig. 11. FFTF Sampling Cel1 


\section{REFERENCES}

1. W. H. Olson, Sampling and Analysis of EBR-II Sodium, USAEC report ANL-7844 (1971).

2. V. M. Kolba et al., Carbon Meter-Equilibration Module for LMFBR's: Design and Operation, USAEC report ANL-7941 (1972).

3. Sodium Technology Quarterly Report, April-June 1972, USAEC report ANL-7957 (1972).

4. RDT Standard F 3-40, Methods for the Analysis of Sodium and Cover Gas, January 1973.

5. V. M. Kolba et $a$. , Oxygen-Hydrogen Meter Module for LMFBR's: Design and Operation, USAEC report ANL-7940 (1972).

6. D. L. Smith, An Equilibration Method for Measuring Low-Oxygen Activities in Liquid Sodium, Nuc1. Techno1. 11, 115 (May 1971). 
APPENDIX A

REMOTE TESTING OF THE MULTIPURPOSE SAMPLER ON APPARATUS
FOR MONITORING AND PURIFYING SODIUM (AMPS)

A program to test the multipurpose sampler has been conducted by the ANL Sodium Technology Project. The principal objective of this program was to demonstrate the feasibility of remote operation of the sampler. Other related objectives included (1) developing special tools and handling techniques, as required, (2) pinpointing potential problem areas and finding simple workable solutions for them, and (3) estimating the time required for each remote operation.

The test results are presented below. Accordingly, for each component and for each operation involving that component, a description of (a) the procedures followed, (b) the results of the operation, (c) the time required for the operation, (d) precautions that should be taken, (e) special tools (including sketches of the tools) and procedures that are needed, and ( $f$ ) suggested design improvements. This test program was a success; all objectives were met and no major problems were encountered. The composite results indicate that the multipurpose sampler is a device that can be remotely operated. 


\section{Dry Tests}

These tests were done on a MS that had been operated with sodium. The furnaces were installed prior to the remote testing. The Grayloc closures used for these tests were of two types; a two-jaw (4-stud, 8-nut) for installations where "hands-on" operation is permissible, and a three-jaw single-bolt type for use on remote installations. The two-jaw type was tested on both upper and lower closures. Later, a three-jaw single-bolt type was tested on the upper closure. Both types provided satisfactory seals and were employed when making sodium sampling and wire equilibration runs at $700^{\circ} \mathrm{F}$ and at $1382^{\circ} \mathrm{F}$, respectively.

\section{Component}

I. Top Connector and Sample Holder

1. Upper Grayloc

2. Sample Holder

3. Upper Grayloc
Open Connector

Remove Holder

Remove Seal Ring
This operation was carried out using an impact wrench fitted with a 1-1/4-in. socket head. The required torque was obtained by controlling the power to the wrench with a Variac. The impact wrench was held by a sling (See Fig. 1-A) which was suspended from the crane in the cell. One manipulator held and guided the wrench as it was moved into position with the crane. Time required for loosening the four bolts was about $8 \mathrm{~min}$.

A 0 to $100 \mathrm{lb}$ scale was suspended from the crane hook, and the sling (see Fig. 2-A) on the insert-holder assembly was hung over the hook on the scale. Normal load on the scale with a clean insert and insert holder was about 6 pounds. The insert holder was generally pulled free from the seal ring before the scale indicated a total load of 10 pounds. Time required for this operation was about 3 min.

The seal ring was not found to be wedged into either of the hubs and was easily picked up and removed with the manipulator. Time required was less than 2 min. 


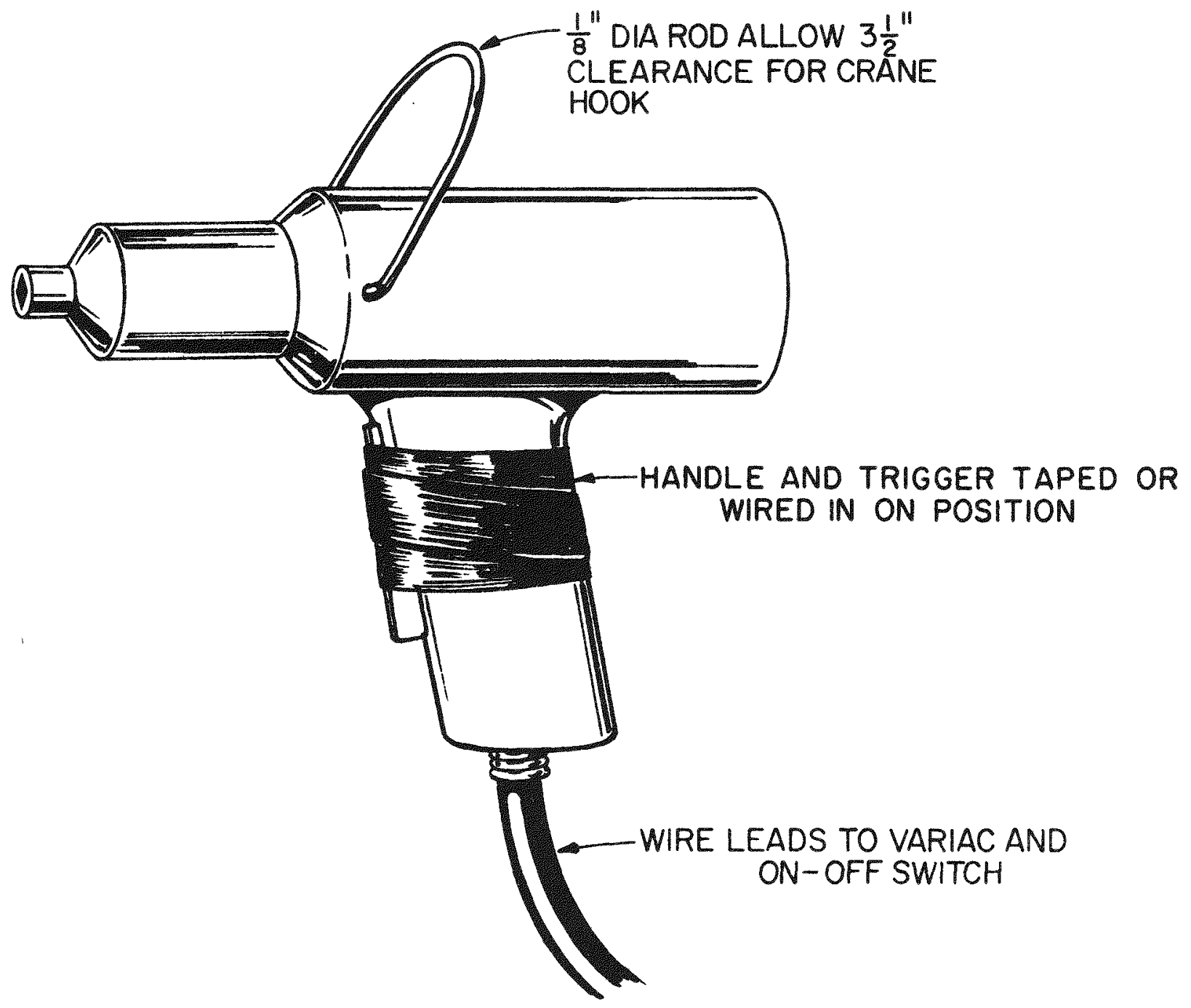

Fig. 1-A. Impact Wrench and Sling 


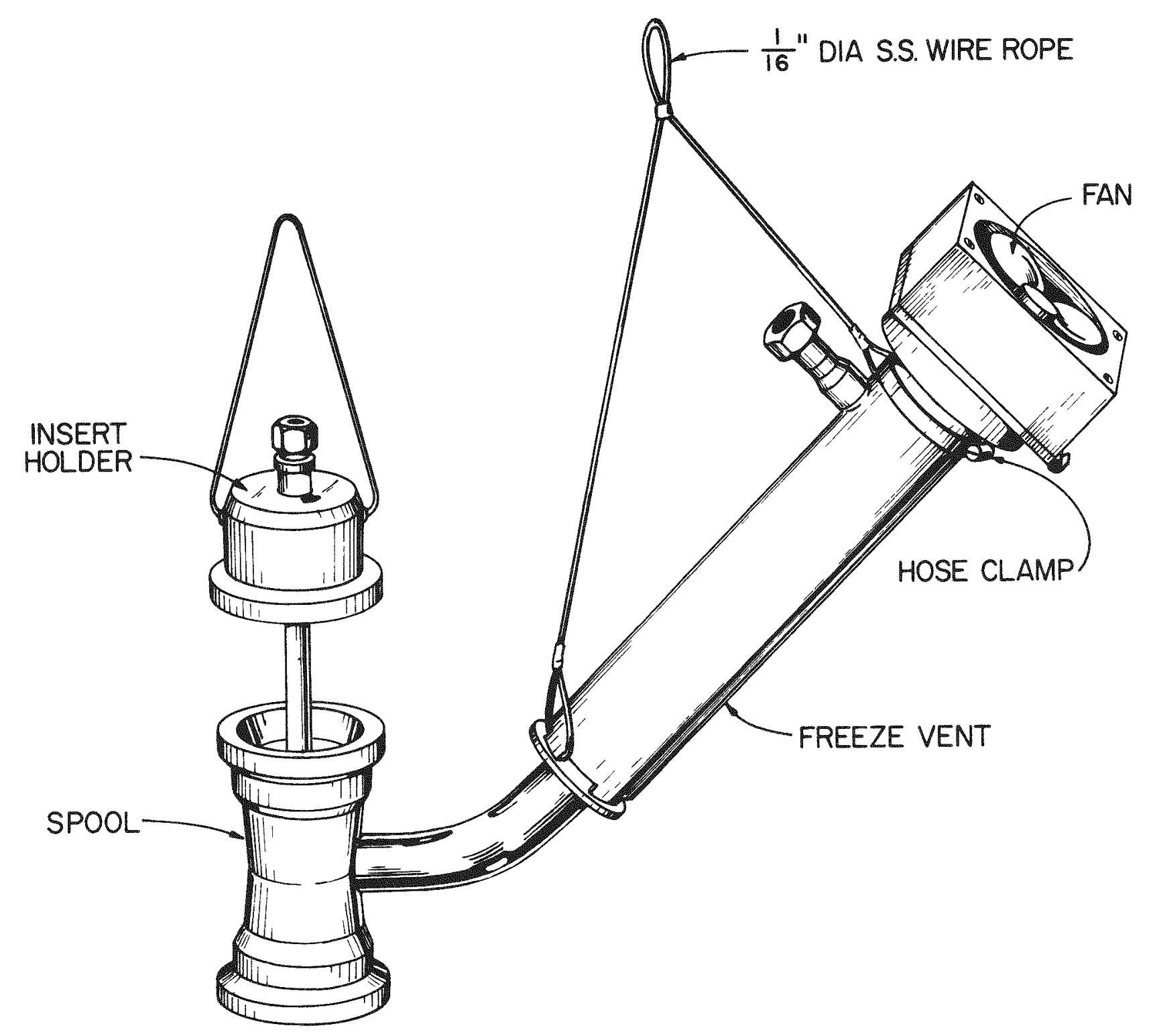

Fig. 2-A. S1ing Arrangement for Lifting Spool Pierce and Freeze Vent 
4. Upper Grayloc

5. Upper Grayloc

6. Upper Grayloc

7. Sample Holder

8. Upper Grayloc
Check Seal Surfaces

Clean Seal Ring and Seal Surfaces on Hubs

Replace Seal Ring

Replace or Reseat Holder

Close Connector
Comments

A mirror and light (optional) were required to check sealing surface on the lower hub. Seal ring and upper hub on the insert holder assembly can be brought near the cell window for close examination. Minimum time required was about 5 min.

Because alcohol and 1int-free wipes or tissues held by the manipulators were used, this operation was rather awkward. Since the amount of cleaning might vary widely, we estimate a minimum time of 5 min will be required.

A specially made swab on a small shaft, driven by a small power tool, might facilitate the cleaning of the seal surfaces. We suggest, however, that spare clean seal rings be available in the cell and that the used, dirty seal rings be brought outside the cell for cleaning.

No problem; time required was less than 2 min.

The insert holder sling was attached to the crane hook and the crane was positioned directly over the open hub. With seal ring in place, the insert holder was slowly lowered into the MS. Time required for the operation was about 2 min.

The two jaws of the upper Grayloc were held in place by hand and the studs put in place. The nuts were threaded on the studs by hand until snug. Further tightening was accomplished using the impact wrench and sling arrangement described in the first item of this section. 
II. Sampler Leak Check

1. Upper Grayloc
Leak Check

Connect and Disconnect
After breaking and remaking the upper connection, it can be leak-checked in the following manner: The MS is evacuated to a TC gauge reading of 150 to $160 \mu \mathrm{A}$. (See Fig. 3-A for the vacuum-gas plumbing arrangement used for leak checking.) If this can be accomplished, it is relatively certain that there are no major leaks in the system. Next, the vacuum pump isolation valve is closed, and the vacuum decay on the $\mathrm{TC}$ gauge is observed. The current reading should level off. For our system, the current was about $140 \mu \mathrm{A}$, but the value depends on the volume of the isolated system. When it is established that the vacuum is holding, the valve that was used for isolating the vacuum pump is opened. The gauge reading should rapidly increase to its earlier value of 150 to $160 \mu \mathrm{A}$, if there are no major leaks in the system.

The connect and disconnect referred to here are at the Swagelok connection in the insert holder assembly. Initially, the PRB was lowered through the Swagelok connector until the PRB touches the bottom of the wall. Then, the Swagelok nut was tightened enough to set the ferrules. Disconnecting then requires backing off the nut enough to free the PRB from the connections. The only tool required is a small wrench fitted with clips for holding with the manipulator fingers. Time required for making or breaking this connection was about $2 \mathrm{~min}$. 


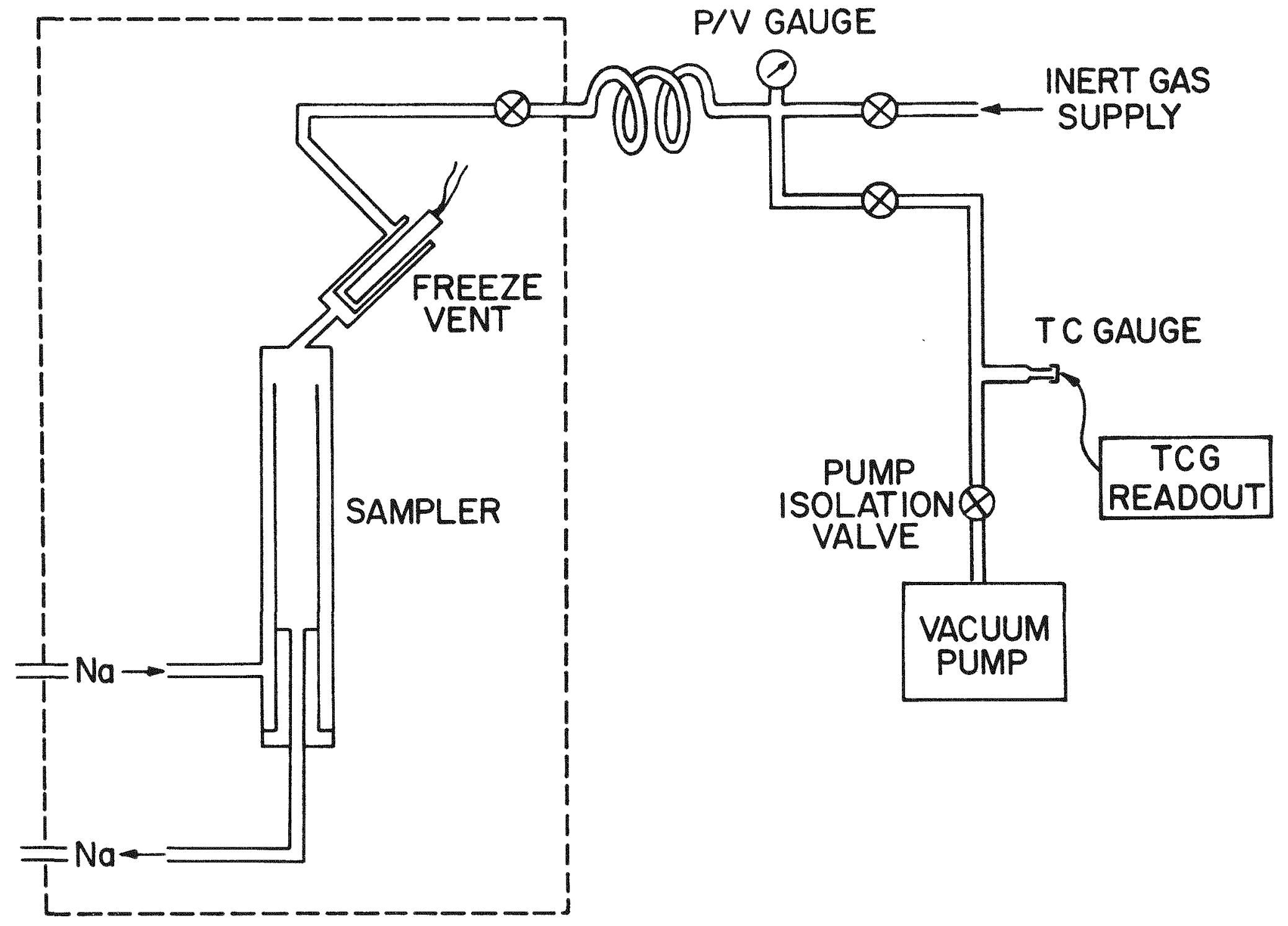

Fig. 3-A. Piping Arrangement for Leak Checking 
Component

IV. Freeze Vent

1. Freeze Vent Fan

2. Freeze Vent Heater

3. Freeze Vent Fan

V. Electrical and Instrument Leads

1. Power Leads at Furnace

2. Thermocouples at Furnace or Other Locations
Remove and Replace

Bring Close to Duct

Unplug and Plug

Unplug and P1ug

\section{Comments}

Prior to handling the fan, the power to the fan is turned off on the control console and the power leads should be disconnected. The reason for this is to avoid possible fan-blade breakage. Disconnecting the power lead and folding back the hinged fan required about 1-2 min.

This operation involves disconnecting the heater plug from the power strip and sliding the heater out of the heater well in the freeze vent. Time required was about $2 \mathrm{~min}$.

To replace the heater, a mirror may be needed to locate the heater well. Once the well is located, the heater slides in freely and the plug is inserted into the power strip. Again, time required was about 2 min.

The hinged fan is raised and brought into contact with the duct. Time required was 1 min or less.

See Fig. 4-A for suggested modifications to hinge on freeze-vent fan.

These operations present no problems when the manipulator fingers are equipped with rubber pads and so-called "finger nails." Time required to plug or unplug a single power or TC lead was about 1 min.

See preceding comment. 


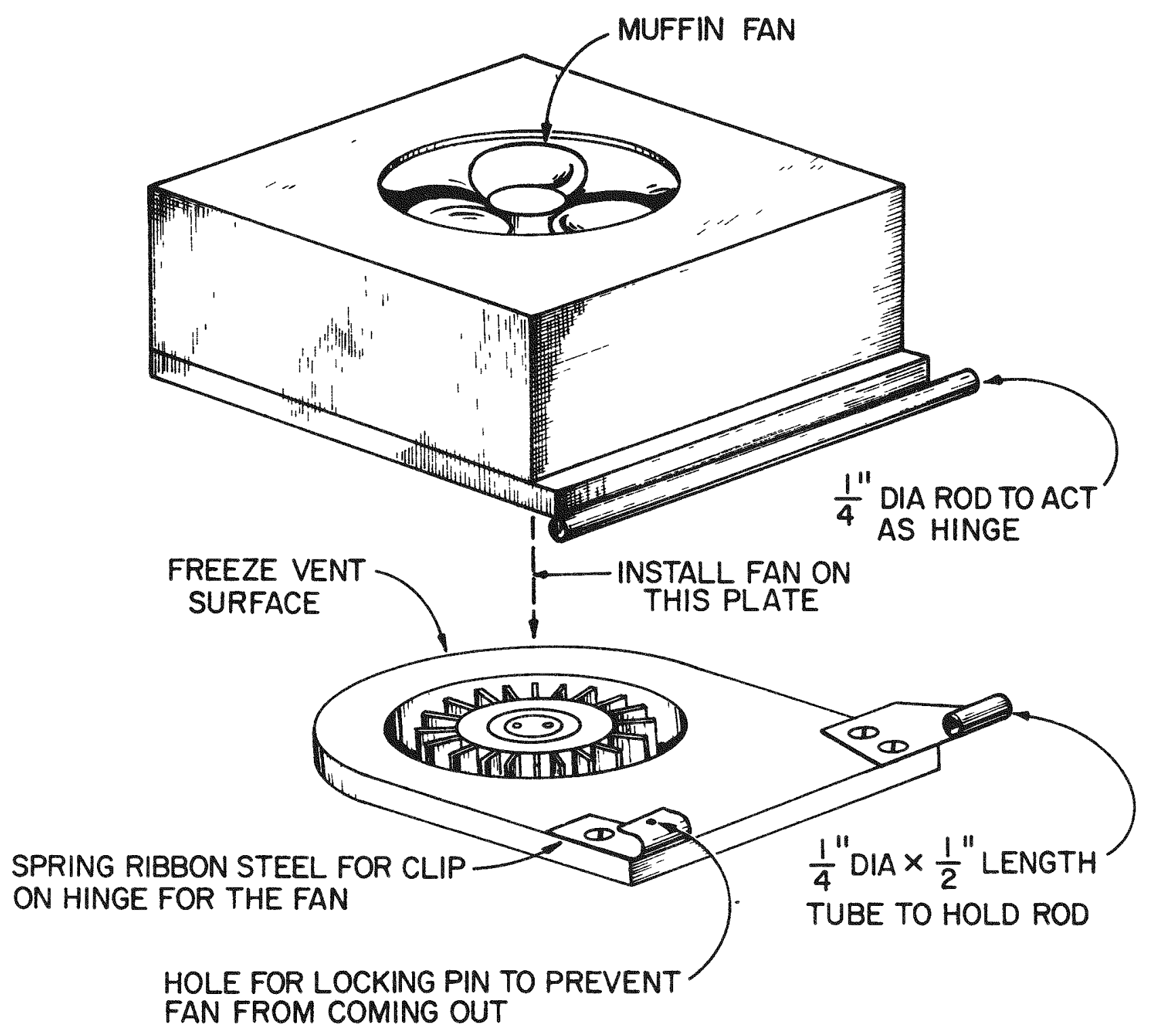

Fig. 4-A. Suggested Fan Hinge Modification 
VI. Gas - Vacuum Line

1. Conoseal

2. Conoseal

3. Conoseal

4. Conoseal

5. Conoseal
Check and Clean Sealing Surfaces

Install New Gasket
Separate Lines

Remove Gasket
Unthread Nut

The tool for this operation was a standard 1-1/8 in. open-end wrench fitted with finger clips for use with the manipulators. Time required to unthread the nut was about 5 min.

No problem. By means of one manipulator, the line was pulled away from the connector on the freeze vent and held by locking the manipulator. Time required was about $1 \mathrm{~min}$.

This was accomplished with one manipulator, and a small screwdriver fitted with clips attached to the second manipulator. The gasket generally remains wedged into the female part of the Conoseal and is removed by carefully prying loose with the screwdriver. Care should be taken to avoid scoring the sealing surfaces of the flange. Time required to complete this operation was about $2 \mathrm{~min}$.

It is expected that the sealing surfaces on this fitting will remain comparatively clean. Neither sodium nor sodium vapor is expected to accumulate at the seal under normal operating conditions. A mirror and swabs saturated with ethanol were used for inspecting and cleaning the sealing surfaces. The operation required from 5 to 7 min.

The new gasket was easily picked up with forceps fitted with finger clips and set into the flange part that is connected to the freeze vent. The operation is easily accomplished and requires about $1 \mathrm{~min}$. 
6. Conoseal

\section{Conoseal}

VII. Spool Piece Replacement

1. Freeze Vent TC's

2. Freeze Vent Fan

3. Freeze Vent Conoseal
Operation

Reposition Line and Tighten Nut

Leak Check

Unplug

Unplug

Loosen Nut (Do not unthread)
Comments

The line was brought into position so that the flange faces mated and was held there with one manipulator. The Conoseal nut was rotated with the other manipulator until it was threaded up snug on the female flange. Final tightening was accomplished using a standard $\mathrm{ft}-1 \mathrm{~b}$ torque wrench which was suspended from the crane hook by a sling. A 1-1/8-in. open-end wrench head was fitted to the working end of the torque wrench. The torque wrench was then held with one manipulator, and by positioning with the crane, the open-end wrench head was brought into place around the Conoseal nut. The other manipulator was then used to apply the required force, $24-35 \mathrm{ft} 1 \mathrm{bs}$, to make the seal. With the Model 8 manipulators, we were able to tighten to $32 \mathrm{ft}$ lbs. Time required for the operation was $5 \mathrm{~min}$.

Leak check as in Section II.

We removed or detached the freeze-vent thermocouples (TC) instead of unplugging them. The two TC located in the space adjacent to the cooling fins were merely pulled out and laid aside (not disconnected). All other TCs on the freeze vent were removed by loosening the clamps that held them and then placed aside during the replacement of the spool piece. Time required for these operations was about 3 to $4 \mathrm{~min}$.

No problem; the fan was easily unplugged. Time required was 1 to $2 \mathrm{~min}$.

Same tool was used as described in Section VI for this operation (wrench fitted with manipulator finger clips). Time required was 1 to $2 \mathrm{~min}$. 
Component

4. Pt Resistance Bulb Connection

5. Upper Grayloc

6. Sample Holder

7. Lower Grayloc

8. Freeze Vent

9. Freeze Vent and Spool Piece

10. Freeze Vent and Spool Piece

\section{Operation}

Disconnect

Open Connector

Remove

Open

Unthread Nut and Disconnect Line

Remove

Check and Clean Seal Surfaces
Comments

The Swagelok nut is backed off using a small open-end wrench fitted with finger clips and then the PRB is raised out of the thermowell and carefully laid aside. Time required for both operations was about $2 \mathrm{~min}$.

The 2-jaw, 4-stud-type Grayloc and the 3-jaw, single-bolttype Grayloc were used in our testing program. The nuts were backed off or loosened using the impact wrench. Time required for loosening the $2-j a w, 4-s t u d$ connector was about 5 min.

See Section I, item 2. The upper seal ring is also removed at this point (see Section I, item 3).

Prior to opening the lower Grayloc, a sling was made (see Fig. 2-A) and attached to the upper and lower part of the freeze vent. A loop section of the sling was hung over the crane hook which had been brought into position above the freeze vent and spool piece. After raising the crane enough to make the sling taut, the nuts on the lower Grayloc were loosened, using the impact wrench. Total time required, after the sling was hung over the crane hook, was 5 to $6 \mathrm{~min}$. The Grayloc jaws were removed by hand.

See Section VI, items 1 and 2 .

At this point, with the Conoseal connection broken and separated, the freeze vent and spool piece were lifted and moved into position over a working area and then lowered to the floor of the cell. Time required for this operation was 5 to $10 \mathrm{~min}$.

See Section I, items 4 and 5. 
Component

11. Lower Grayloc

12. Lower Grayloc

13. Lower Grayloc

14. Lower Grayloc

15. Freeze Vent and Spool Piece

16. Lower Grayloc

17. Freeze Vent and Spool Piece

18. Lower Grayloc

19. Freeze Vent and Spool Piece
Operation

Remove Sea1 Ring

Check Seal Surface

Clean Seal Ring and Seal Surfaces

on Hubs

\section{Replace Seal Ring}

Locate and Replace

Install and Tighten

Instal1 Plugs

in Openings

Leak Check

Remove Plugs
Comments

See Section I, item 3.

See Section I, items 4 and 5 .

See Section I, items 4 and 5 .

See Section I, item 6.

The sling was attached to the replacement spool piece. The sling was placed over the crane hook and the crane moved into place over the lower hub (seal ring already replaced). The crane was slowly lowered until the spool piece came to rest on the seal ring. At this point, the Conoseal fittings were checked to make sure that they were properly aligned. Time required for these operations was about $5 \mathrm{~min}$.

The two jaws of the lower Grayloc were positioned and the studs and nuts were put in place (by hand). Final tightening was accomplished using the impact wrench. Time required was about $5 \mathrm{~min}$. (We suggest that a support plate be designed and attached to the MS which will serve to hold or support the lower Grayloc jaws when the connector is opened.)

In preparation for leak checking the lower Grayloc connection, clean solid rubber stoppers (a \#12 and a 非0) were plugged into the upper hub on the spool piece and into the Conoseal fitting on the freeze vent. Time required was bout $4 \mathrm{~min}$.

Leak check as in Section II.

The removal of both stoppers required from about 3 to 5 min. 
20. Freeze Vent Conoseal

21. Spool Piece

22. Upper Grayloc

23. Sample Holder

24. Upper Grayloc

25. MS System Closures

VIII. Furnace Replacement

1. Lower and Upper Furnace

2. Lower and Upper Furnace

\section{Lower Furnace}

4. Lower Furnace

5. Lower Furnace

6. Lower Furnace
Clean Sealing Surfaces, See Section VI, items 4, 5, and 6.

Instal1 Gasket and

Tighten Connection

Clean Seal Furface

Replace Seal Ring

Insta 11

Close Connector

Leak Check

Instal1 Power

Leads

Insta11 TC Leads

Place $1 / 2$ sections of furnace on MS

Lock Furnace

Halves

Unlock Furnace

Halves

Remove and Replace Furnace Halve
See Section I, item 4 .

See Section I, item 6 .

See Section I, item 7.

See Section I, item 8.

See Section II, item 1.

No problems were encountered when installing power leads or $T C$ leads to the upper furnace. The installation of leads on the lower furnace could not be checked out because the lower furnace on our MS unit sits down in a well. It is believed, however, that in an installation where the floor plates can be removed to gain access to the lower furnace, power or TC lead installation will not be a problem. The estimated time required to install all leads, excluding floor-plate removal, was $10 \mathrm{~min}$.

Since our MS installation arrangement on AMPS was different than the planned FFTF arrangement, a different approach was taken to the replacement of the lower furnace. However, the technique developed may be applicable to the FFTF system. The first step was to unlatch the upper furnace and move both halves back and away. Next, a special sling was made (see Fig. 5-A), which allowed both halves of the bottom furnace to be lifted simultaneously with the crane. When the top of the lower furnace made contact with the upper support ring on the MS, the furnace was held at that elevation. The next step was to slide a 


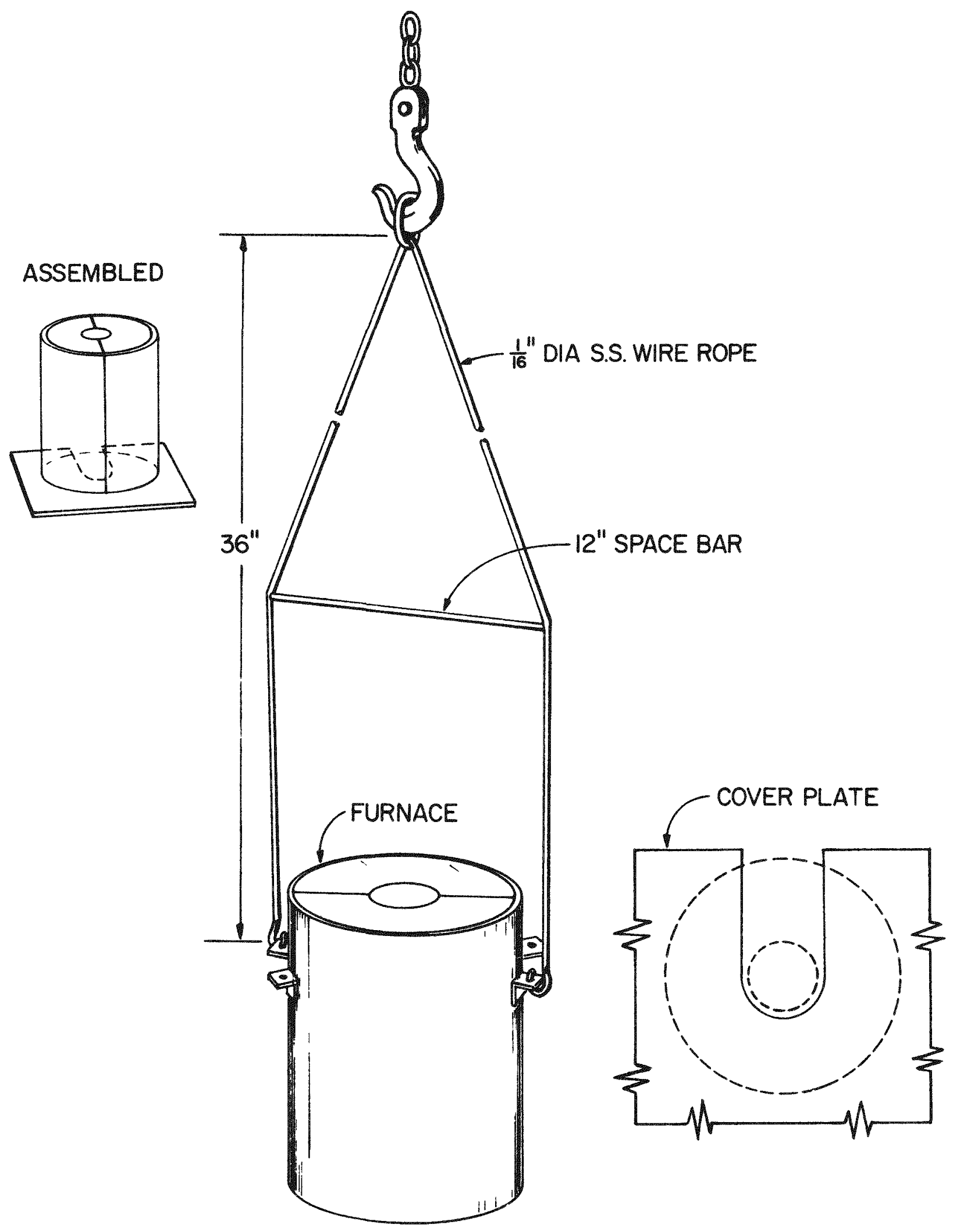

Fig. 5-A. Furnace Sling 
support plate under the furnace. The plate was long enough to span the well or opening in the floor of the sampling cell. After the plate was in place, the furnace was lowered onto the plate and the sling was removed. Next, we proceeded to loosen the screw-type band clamp that held the two furnace halves together.

The band was loosened only enough to allow it to drop down to the support plate. The next step was to disconnect TC and power leads from the furnace half that was to be replaced and then attach both sling hooks to the lugs provided for lifting. After raising the crane hook enough to take the weight of the furnace off the support plate, the crane was moved horizontally until the furnace was no longer beneath the support ring on the MS. From this position, it could be raised and moved out into a work area in the cell.

Replacing a lower furnace half requires all of the operations mentioned in Section VIII above, but in reverse order. Briefly, these are attaching the sling to the replacement furnace, moving it into position on the support plate, attaching the band around the two halves, and connecting the power and TC leads. Next, the lower furnace is lifted to remove the support plate and then lowered into place. After disconnecting the sling, the upper furnace halves are brought together and latched, thereby completing the operation. Time required to accomplish replacement of one half of the lower furnace by the procedure described above was $1 \mathrm{hr}$.

7. Upper Furnace
Place $1 / 2$ Sections of Furnace on Hinges
No problem. By using the sling, crane, and one manipulator, the furnace half was raised and guided into position. Lugs on the furnace were aligned with pins on the support hinge and the furnace slowly lowered into place. Time required was about 10 min per furnace half. 
8. Upper Furnace

9. Upper Furnace

10. Upper and Lower Furnace

\section{Insert Hand1ing}

1. Inserts (3)

2. Archive-cup Insert

3. Equilibration
Lock Furnace

Unlock, Swing Open

Plug Leads into Strip

Attachment/ Remova1

Installation of Cup and Assembly of Insert

Insta11 Samples
Comments

By using both manipulators, the upper furnace halves were brought into face-to-face contact and then the locking latch was flipped upward. Time required for this operation was 1 min.

This operation was accomplished by pulling the latching device forward and then swinging each furnace half outward and away from the MS. Time required was 1 min.

Thermocouple and power leads were easily plugged into the receptacles on the back wall of the cel1. Time required was about 1 min or less per plug.

The inserts were stored in a rack on the back wall of the cel1. Removing an insert from the rack and attaching it to the insert holder required about 1 min. A special handling clip, which is shown in Fig. 6-A, was made and fitted to one of the manipulator fingers. The clip facilitates holding and twisting the insert onto the bayonet-type lock. Time required for removal from rack to attaching on the insert holder was $1 \mathrm{~min}$. The same time is required for the reverse operation.

A cup is placed on the pedestal of the bottom cap, and this assembly is placed into the insert and the bottom cap attached. This operation requires about $1 \mathrm{~min}$.

Sma11 tabs or smal1-diameter wires, singly or on holders, can easily be loaded into the equilibration insert using forceps fitted to a manipulator finger. Time required depends on the number of specimens. It is recommended that this operation normally be performed manually outside the sampling cell. 


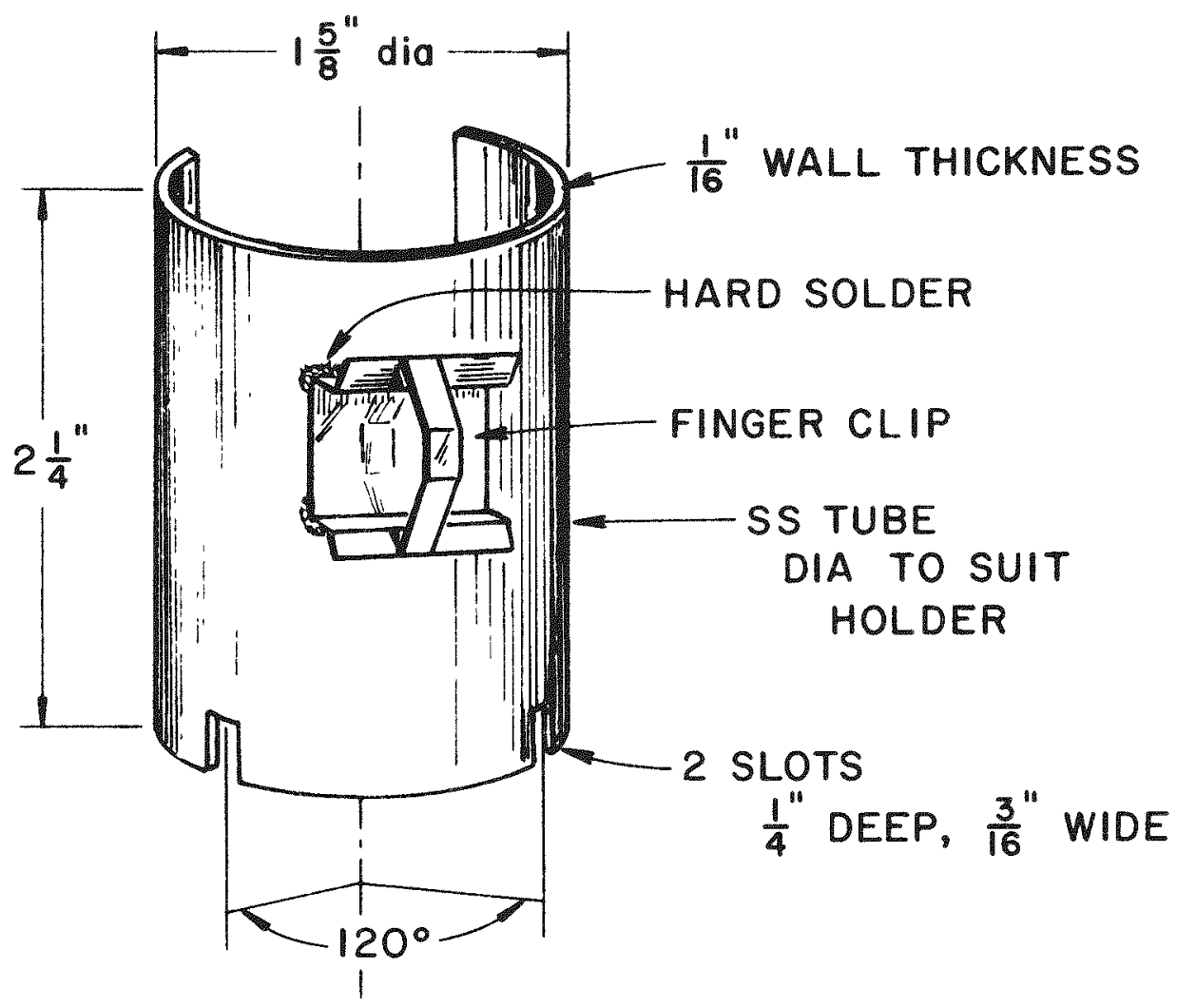

Fig. 6-A. Tool for Holding Inserts 
4. Equilibration Insert

5. Inserts ( 3 per container)

6. Container
Operation

Install Funnel

Place Inserts in and Remove Them from Container

Cap and Uncap
Comments

No problem; less than 1 min was required to install the funnel. The insert, with specimens or holder in position, is held by one manipulator. The funnel is held by the second manipulator and carefully lowered into the insert until the funnel rests on the projections in the insert. Normally, these operations should be performed outside of the remote facility.

The individual inserts were easily loaded into and removed from the containers. Forceps fitted with finger clips were used. Time required was 1 min or less to load and about the same amount of time to unload.

The time for capping varied. If the threads happened to cross, it was necessary to back off the cap and try again; in this case, it might take 2-3 min to get the cap snugged down on the container with the manipulator. At other times, when there were no problems with crossed threads, the container could be capped in about $1 \mathrm{~min}$. Uncapping requires about 1 min. 


\section{Wet Tests}

The wet testing was carried out in air, that is, without an inert atmosphere to simulate the FFTF sampling cell. Therefore, operations were not carried out which required heating and melting of sodium ouside the closed MS to accomplish disassembly of the component.

Component

\section{Sampling Operation \\ 1. Archive-cup Insert Sample Holder}

2. Archive-cup Insert
Operation

Remova1

Instal1 Cup and Bottom Cap in Insert
Comments

After opening the upper Grayloc, the archive-cup insert and insert holder were removed as described in Section I, item 2. There was increased drap on the sample holder and insert when it was 1ifted out of the MS owing to droplets of frozen sodium adhering to the inner wall of the shroud and the outer wall of the archive-cup insert, and because of a little sodium condensate on the lower vapor baffles. Total pull as measured on the load indicator (scale) did not exceed 16 lbs.

The insert could not be disconnected from the insert holder with the manipulators because of bonding between parts by frozen sodium. In an attempt to minimize the sodium bonding between the insert and the insert holder, the upper part of an archive-cup insert was modified as shown in Fig. 7-A. Testing of this insert confirmed that the change was an improvement. In a controlled atmosphere cell, with the capability of using a heat gun, disconnecting the modified insert from the insert holder should not be a problem. The type of modification shown in Fig. 7-A is recommended for all inserts.

See Section IX, item 2 for the installation method. One minute was required to install the cup and assemble the insert, using manipulators and an insert-holding tool. (Preassembly of the inserts outside the sampling cell should be considered.) 


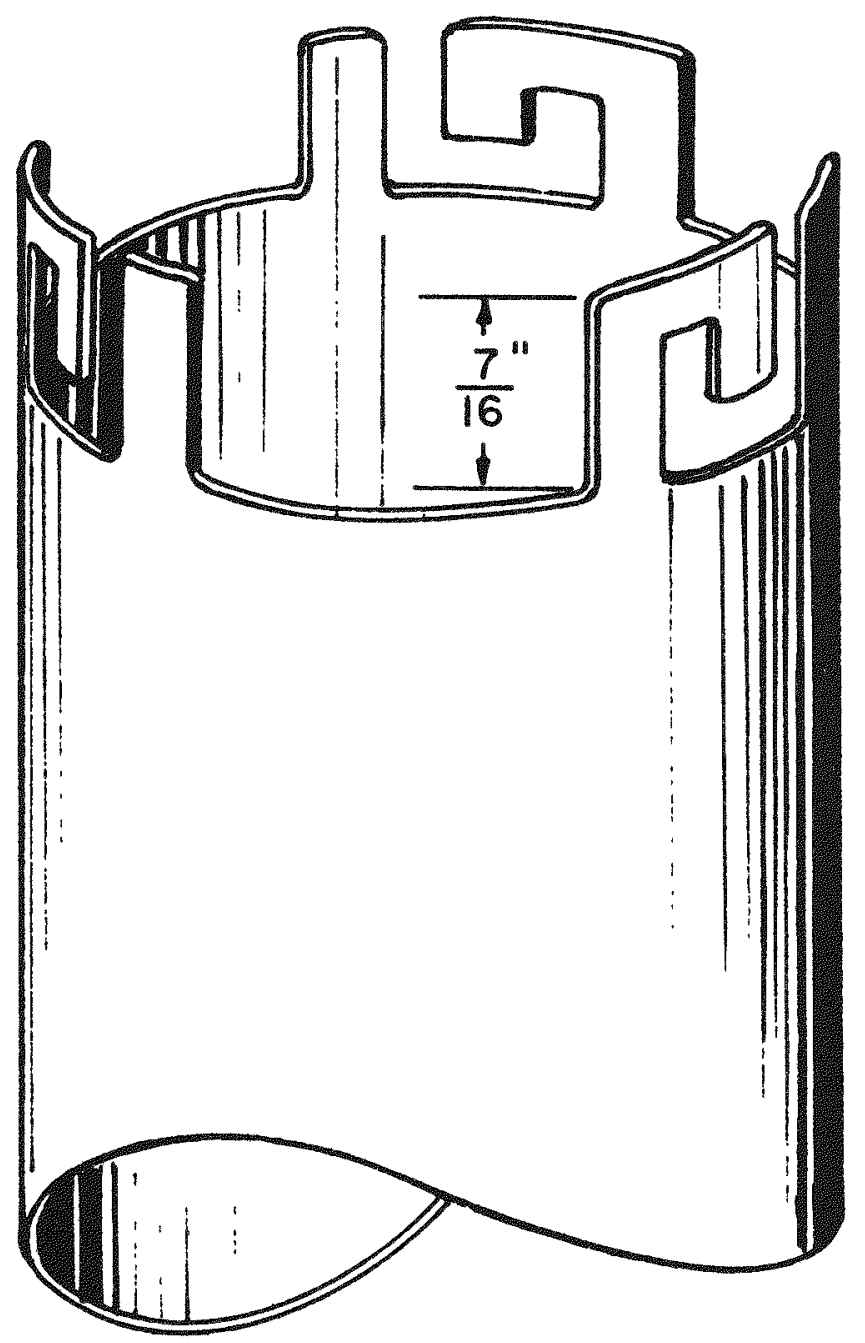

Fig. 7-A. Modified Archive-cup Insert 
3. Archive-cup Insert

4. Archive-cup Insert

5. Equilibration Insert/Sample Holder
Placement in Container

Put Samples In

Removal and Placement in Container

Remova1 Sample Holder

8. Filtration Insert
Remova1 from Container
Comments

Removal of an assembled archive insert from a screw-top container requires about 1 to 2 min. The container is held in a vise and the cap is unthreaded using a manipulator. After the container cap has been removed, forceps are used to lift the insert over the inner lip of the container. Once this is done, the insert will slide out when the container is tilted.

After the insert has been disconnected from the insert holder, about $1 \mathrm{~min}$ is required to load the insert into a container. Capping the container may require from 1 to 3 min. See comments in Section IX, items 5 and 6.

Our "wet" equilibration was carried out using 0.010-in. dia vanadium-wire specimens attached to a small spool. Fig. 8-A shows the insert funnel with spool attached and also gives dimensions of the spool. The wire specimens were attached to the spool by bending the wire through the holes at each end of the spool. The spool and funnel were then loaded into the equilibration insert. These operations were done outside the sampling cell. Preloading the inserts will minimize in-cell handling time.

Connecting the loaded insert to the insert holder requires about 1 min.

As mentioned above, the insert was not removed or disconnected from the insert holder by means of manipulators in the cell (see Section X, item 1). However, once the insert has been disconnected, loading it into a container will require about 1 min. Putting the screw cap on the container may require from 1 to $3 \mathrm{~min}$ (see Section IX, item 6).

Removal tests were not carried out because the filtration insert is to be redesigned to provide a protected filter media.

Same as item 7, above. 


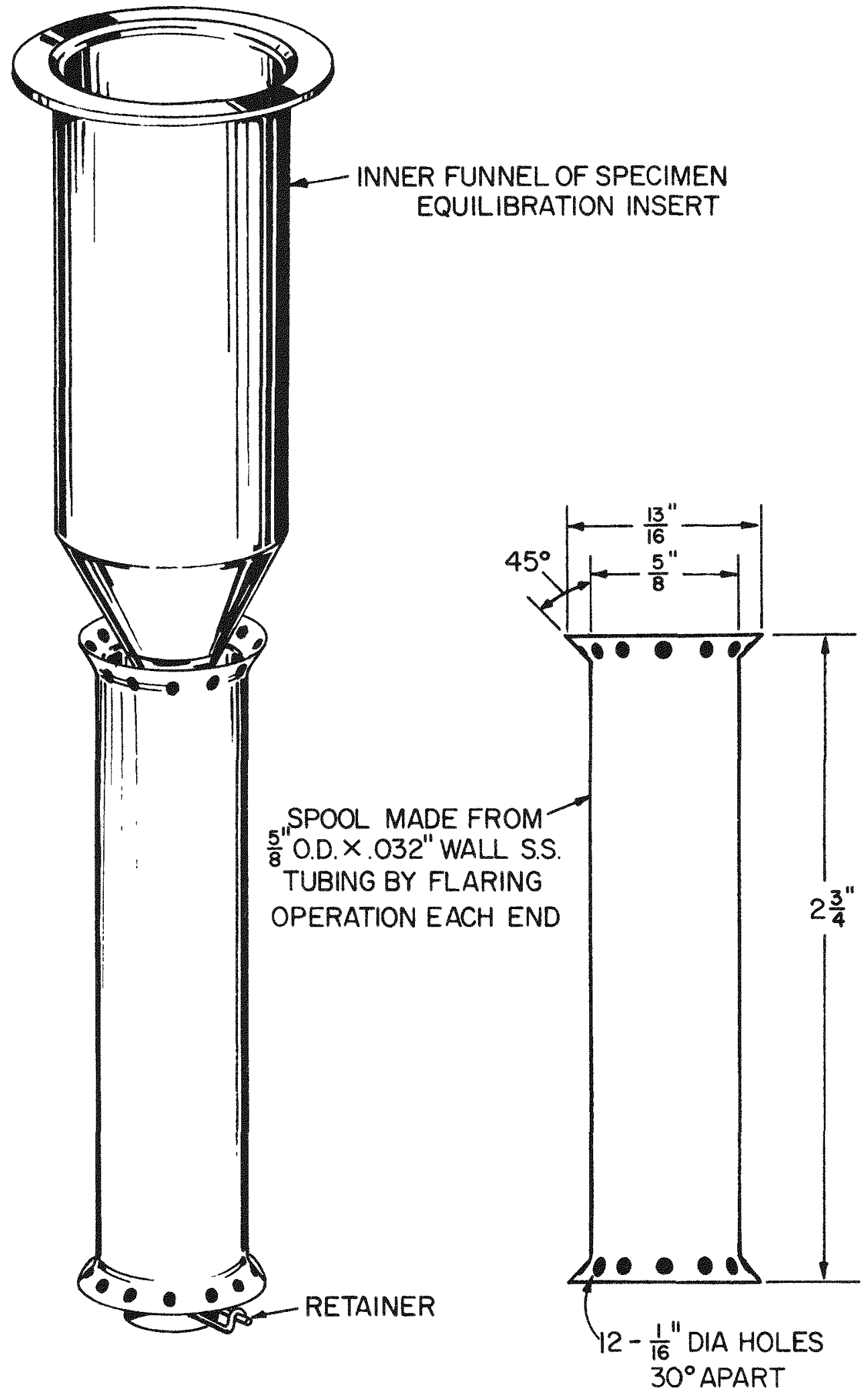

Fig. 8-A. Spool and Funnel Arrangement for Vanadium-wire Equilibration 